REVIEW ARTICLE

\title{
Evolution of Pediatric Cardiology over the Last 50 Years - Part II
}

\section{P Syamasundar Rao, MD*}

Professor of Pediatrics and Medicine, Emeritus Chief of Pediatric Cardiology, Children's Memorial Hermann Hospital, University of Texas-Houston McGovern Medical School, USA

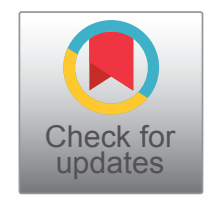

*Corresponding author: P Syamasundar Rao, MD, Professor and Emeritus Chief of Pediatric Cardiology, Children's Memorial Hermann Hospital, University of Texas-Houston McGovern Medical School, 6410 Fannin, UTPB Suite \# 425, Houston, Texas, 77030, USA, Tel: 713-500-5738, Fax: 713-500-5171

\section{Introduction}

The author has just written a book on the evolution of the specialty of Pediatric Cardiology over the last 50 years [1]. The intent of this review is to present a summary of this book. Because of large amount of this material, the review is separated into four parts. In the first part, transcatheter interventions (balloon angioplasty/ valvuloplasty procedures) were appraised. In this paper, transcatheter occlusions and other transcatheter interventional procedures will be discussed.

\section{Atrial Septal Defects}

Initially, the pathologic and pathophysiologic features of atrial septal defects (ASDs) were explained. Then, historical aspects [2-7] of development of percutaneous closure of ASDs were appraised. Indication for ASD occlusion was right ventricular volume overload [8-10]. Contributions of the author with regard to Rashkind's hooked device, buttoned device, and Amplatzer device were separately reviewed.

Following the initial description of the buttoned device in 1990 [11], several modifications of the buttoned device form $1^{\text {st }}$, to $2^{\text {nd }}, 3^{\text {rd }}, 4^{\text {th }}$ generation devices to centering-on-demand were undertaken [13-18]. The immediate (Figure 1 and Figure 2) and follow-up results (Figure 3) of buttoned device closure of ASD at the author's institution $[13,14,19,20]$ and of FDA-approved US [21,22] and international [15-18] clinical trials were individually reviewed; all of the studies showed feasibility, safety, and effectiveness of ASD occlusion with this device. A methodical assessment of all three cohorts of the buttoned device suggested progressive decrease in complications rates, including unbuttoning and better implantation feasibility while preserving the effective occlusion rates with consecutive re-designed versions of the buttoned device $[17,18,23]$.

The author's experience with Amplatzer Septal Occluder (ASO) was then reviewed with the conclusion that ASD occlusion with ASO is feasible, safe and effective in most types of ostium secundum ASD cases with occasional complications $[9,10,24]$. Initially, the ASO device characteristics were described followed by presentation of indications for device closure, the technique of device implantation, and results (Figure 4).

The author and his associates performed the closure of more than 100 ostium secundum ASDs with the ASO as of 2011. The initial series of patients was presented in a poster format [24]. Sixty-five patients were taken to the catheterization laboratory with the intent to occlude their ASDs with the ASO during 2003 to 2011. Devices were not implanted in $4(6 \%)$ patients because of flail or inadequate septal rims. In the remaining 61 patients, transcatheter occlusions were performed with the device. The ages of the patients varied between 3.1 and 17 years (mean 7.9 years). The weights of the patients ranged between 11.8 and $69 \mathrm{~kg}$ with a mean of 29.6 $\mathrm{kg}$. Twenty-four were boys and 42 were girls. The Qp: Qs was 0.9 to 4.5 with a mean of 1.8. The ASD diameter measured by TEE varied between 5.6 and $29.5 \mathrm{~mm}$ with a mean of $14 \mathrm{~mm}$. The ASD diameter measured by

Citation: Rao PS (2021) Evolution of Pediatric Cardiology over the Last 50 Years - Part II. Int J Clin Cardiol 8:226. doi.org/10.23937/2378-2951/1410226 


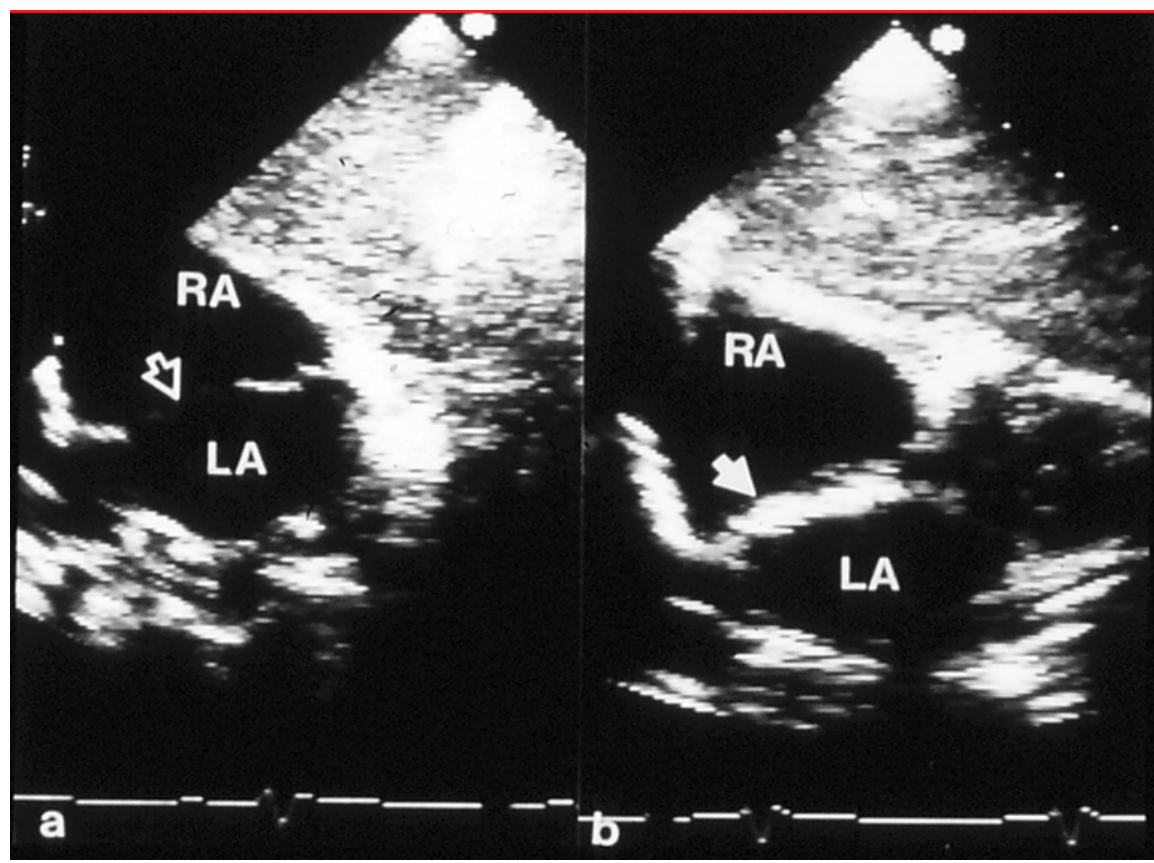

Figure 1: a) Selected video frames from subcostal echocardiographic views showing an atrial septal defect (unfilled arrow) with good septal rims prior to and b) immediately after device (filled arrow) implantation. There was no residual shunt demonstrated by color Doppler imaging (not shown) [12].

LA: Left Atrium; RA: Right Atrium

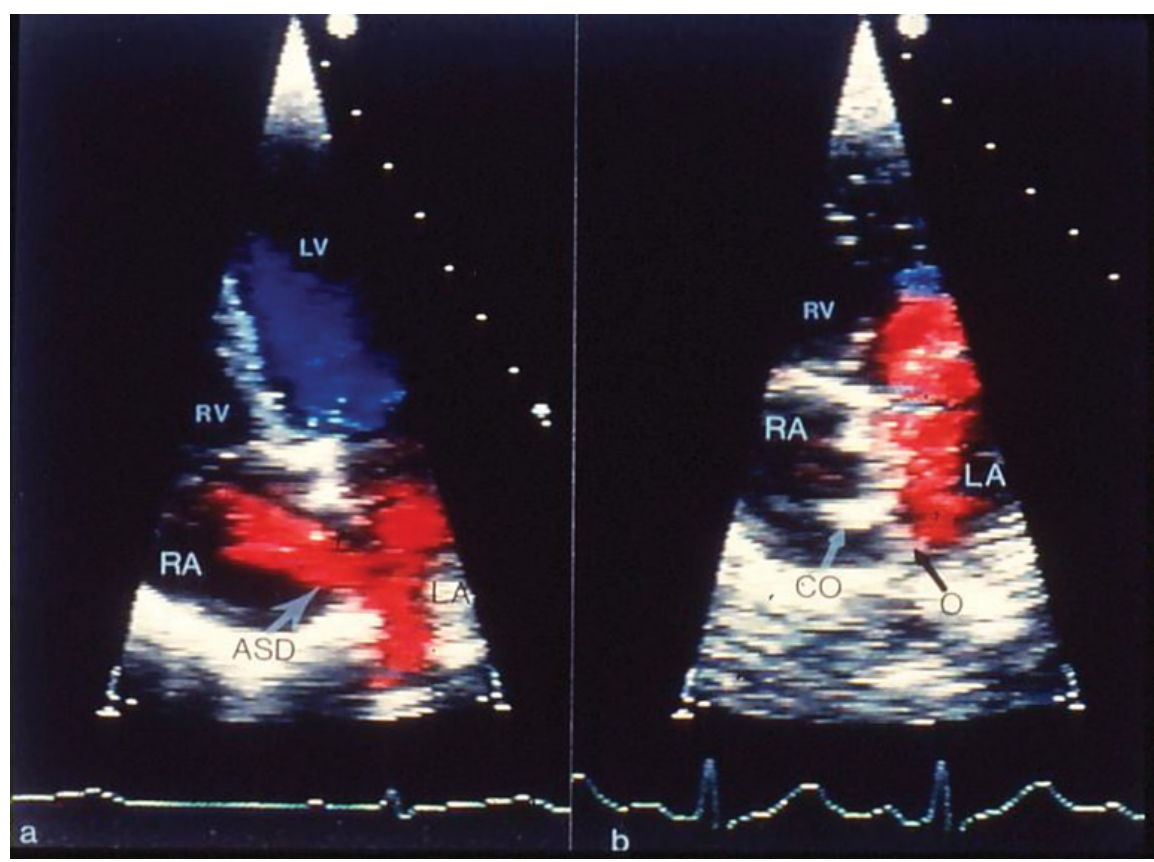

Figure 2: a) Selected video frames from apical four-chamber echocardiographic views of the atrial septum, demonstrating an atrial septal defect (ASD) with a left-to-right shunt prior to and b) 3 months after the implantation of the buttoned device. A black arrow points to the occluder $(O)$ on the left atrial $(L A)$ side of the atrial septum and a white arrow points to the counter-occluder (CO) end on in the right atrium (RA) [13].

LV: Left Ventricle; RV: Right Ventricle

left atrial angiography varied between 5.8 and $25.9 \mathrm{~mm}$ with a mean of $14.5 \mathrm{~mm}$. The balloon-stretched defect diameter was between 10.2 and $25.8 \mathrm{~mm}$ (mean of 17.9 $\mathrm{mm})$. The ASDs were considered complex in $11(17 \%)$ patients (> $26 \mathrm{~mm}$ in five patients, 2 or more defects being present in five patients, and a fenestrated atrial septum in one). The pulmonary artery systolic pressures varied between 11 and $34 \mathrm{mmHg}$, with a mean of 20 $\mathrm{mmHg}$. The devices implanted varied in size between 8 and $34 \mathrm{~mm}$. The most commonly used size was the 20 $\mathrm{mm}$ ASO. The device was successfully implanted in 61 $(100 \%)$ of 61 patients in whom the device was released, or in 61 (93.8\%) of 65 patients catheterized with the intent to occlude the ASD. No device dislodgements were 


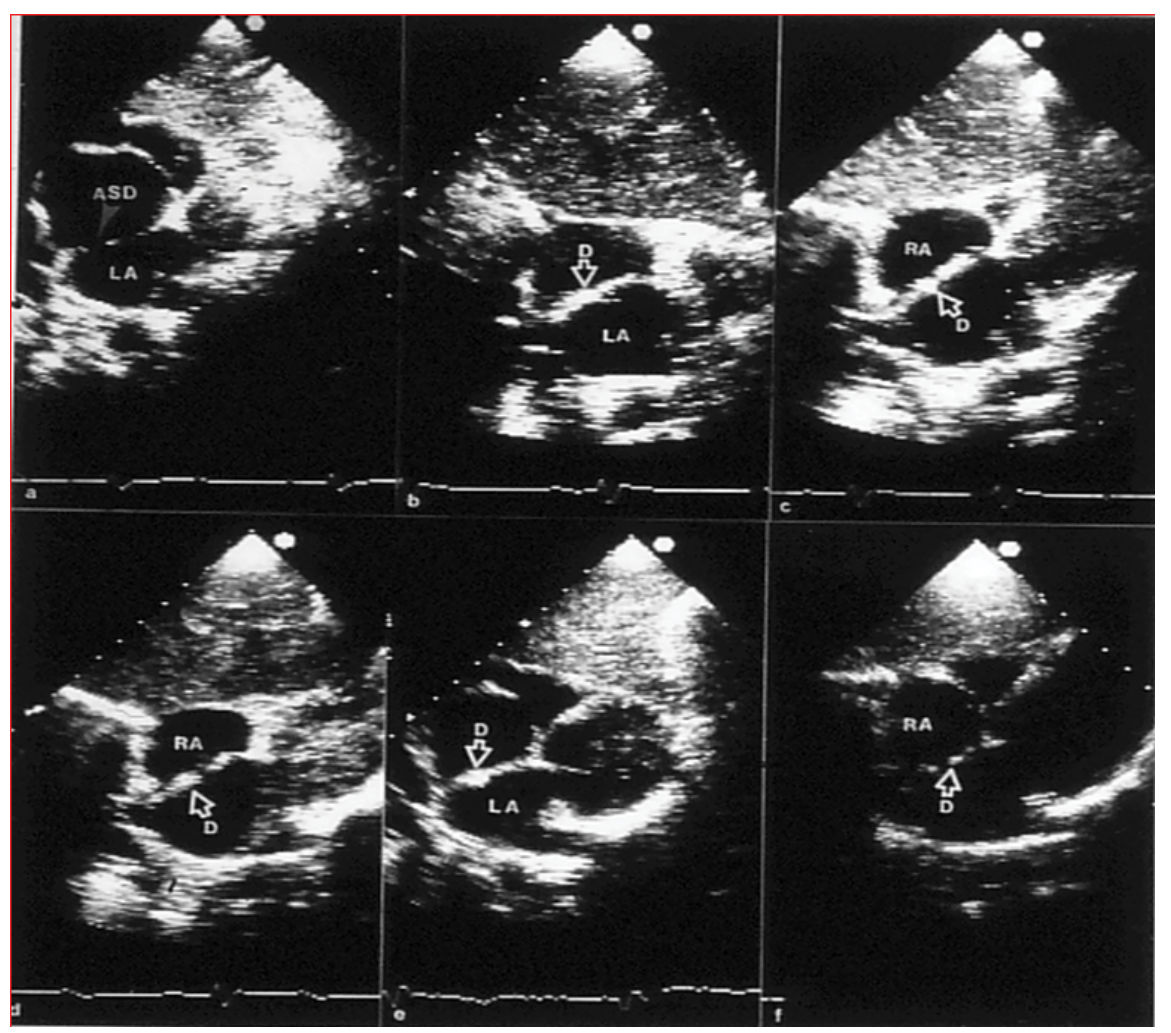

Figure 3: a) Selected video frames from two-dimensional echo studies in the subcostal position of the atrial septum in longaxis view prior to, b) immediately after, and c) at one, d) six, e) 12, and f) 24 months following atrial septal defect (ASD) closure, illustrating the results of transcatheter closure of an ASD with the buttoned device. Note the stable position of the device (D) on the atrial septum (b through e). At 24-month follow-up, the device appears to be incorporated into the atrial septum. On pulsed and color Doppler studies concurrent with two-dimensional echo studies, there was no evidence for a residual shunt (not shown) [20].

LA: Left Atrium; RA: Right Atrium

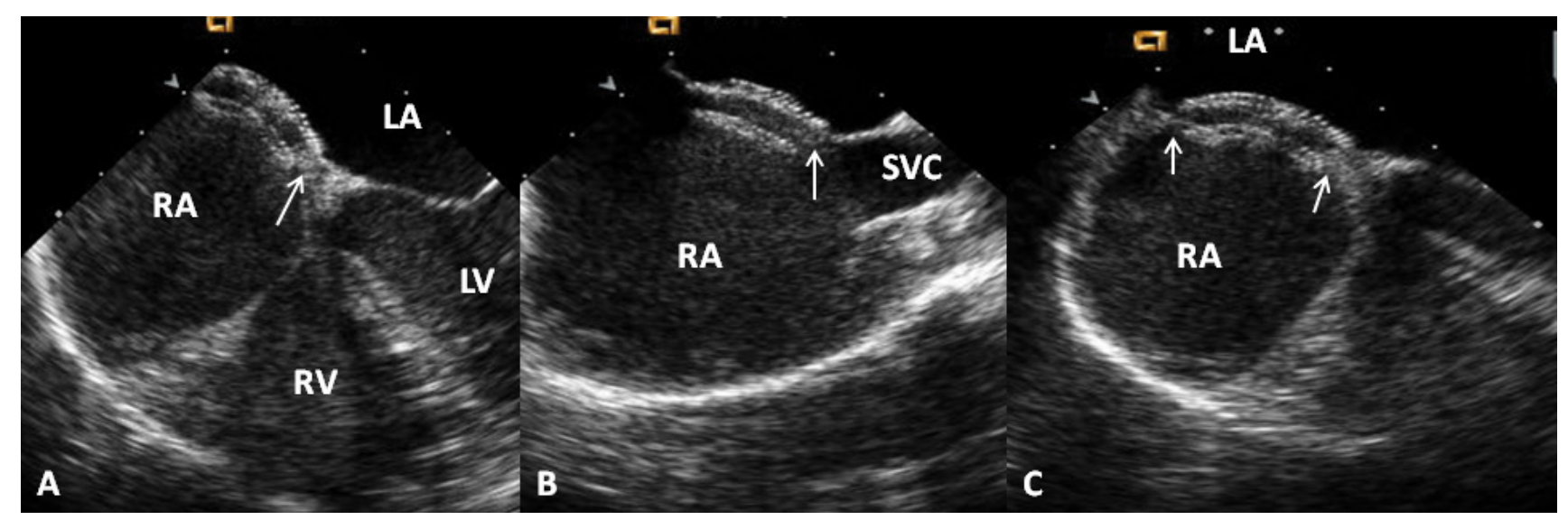

Figure 4: Selected video frames from a trans-esophageal echocardiogram following the implantation of an Amplatzer Septal Occluder to occlude an atrial septal defect, demonstrating the position of both disks in A) four chamber; B) Bi-caval and C) Long axis views. Note that the rims of the defect (thin arrows) are sandwiched between the left atrial (LA) and right atrial (RA) disks [1].

LV: Left Ventricle; RV: Right Ventricle; SVC: Superior Vena Cava

observed. Echo-Doppler studies performed on the day following ASD closure revealed trivial shunts in four patients and small shunts in six patients; the definitions of residual shunts were same as those listed in Table 14-2 of reference [1]. Effective occlusion, defined as an absent $(n=51)$ or trivial $(n=4)$ residual shunt (Table 14-2 of reference [1]) on echo-Doppler studies performed on the day following ASD closure, was shown in 55 patients (90\%). Mild mitral insufficiency $(n=2)$ was detected by color Doppler echocardiography in two patients, which was transient and resolved by the time of the 15-month follow-up visit. The PR interval on the electrocardiogram (ECG) performed on the day following ASD closure varied between 106 to 210 msec with a mean of 146 msec. 


\section{COMPARISON OF CLINICAL TRIAL DATA WITH THOSE WHO HAD HEMODYNAMIC COMPROMISE}

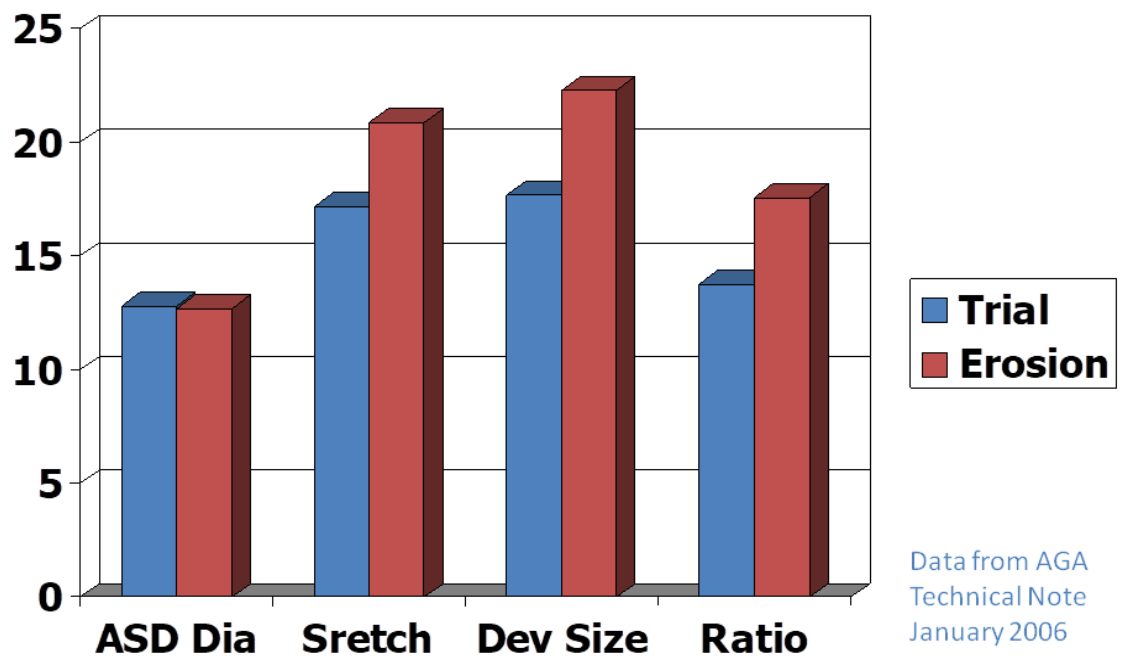

Figure 5: Bar diagram demonstrating the relationships of the data on various atrial septal defects (ASDs) and device sizes between patients without perforation (Trial) and those that had perforation (Erosion). The diameter (Dia) of the ASD was similar in both groups, whereas the stretched diameter (Stretch), device size (Dev size) and ratio of device to ASD (Ratio) were larger in the patients who had perforation than those who did not. Based on these data, it was recommended that devices no larger than $1.5 \times$ the ASD size should be used (Constructed from the data of AGA 2006) [25].

There was evidence for first-degree heart block in seven patients and complete heart block in one. No other complications were encountered. Follow-up data was available in all (100\%) patients from one month to 78 months (mean of 26 months). During this period, one (1.6\%) patient with complete heart block required pacemaker implantation. No other interventions were needed. The PR interval on the ECG performed six months following ASD closure varied between 100 and 204 msec. with a mean of $137 \mathrm{msec}$. There was evidence for first-degree heart block in three patients, second-degree heart block in one patient and complete heart block in one patient (the same patient described in the immediate results section above). Echocardiography revealed the device position to be stable. There was gradual reduction and disappearance of the residual shunts. At six-month follow-up the residual shunts were trivial in two patients and small in five. At one-year follow-up, a trivial residual shunt was seen in one patient. No residual shunts were seen at and beyond 15 months after ASD occlusion. No recurrence of paradoxical embolism was observed in the two patients in whom the atrial defect was closed to prevent further episodes of CVAs/TIAs. No deaths occurred during the entire period of observation [24].

The immediate and follow-up results of the ASO implantations reported by a number of other investigators appear encouraging, with immediate complete closure rates varying from 62 to $96 \%$, which improved to 83 to $99 \%$ at 6 - to 12 -month follow-up $[9,10]$. Other studies in children and adults, as extensively referenced elsewhere [10], showed similar results. These data led us to conclude that ASD occlusion with ASO is feasible, safe, and effective in most ostium secundum ASD cases, with infrequent complications [1].

Device migration/erosion of the aorta during follow-up was seen in 37 out of 35,000 ASO implants, i.e., $0.11 \%(1$ in 1,000$)$ in a large international cohort. This was similar in the U.S., where the figure was 18 out of 15,900 implants, i.e., $0.12 \%$ (1 in 1,000). A review of the data by the Review Board and AGA Medical suggested that device erosion was related to the over-sizing of the device (Figure 5). They recommend against using a device size > 1.5 times the TEE/ICE diameter of the ASD. Carefully following such recommendations is likely to result in the reduction of aortic erosion [1,25].

The Gore HELEX ${ }^{\circledR}$ Septal Occluder device characteristics were also described as well a presentation of indications for device closure, the technique of device implantation, and results [1].

A detailed review comparing all the available ASD closing devices as of that time demonstrated similar feasibility, safety, and effectiveness of all devices [26,27]; however, such appraisal was based on separate clinical trials with each of the devices because there were no randomized clinical trials.

Management of complex ASDs, defined as large defects (> $26 \mathrm{~mm}$ by balloon-sizing), deficient septal rims, multiple or fenestrated defects, and/or atrial septal aneurysms, was reviewed with the resulting conclusion that the majority of complex ASDs can be closed by utilizing either conventional or special techniques and/or devices [25,28-31]. However, ASDs with deficient or absent postero-inferior rim continue to be challenging. 


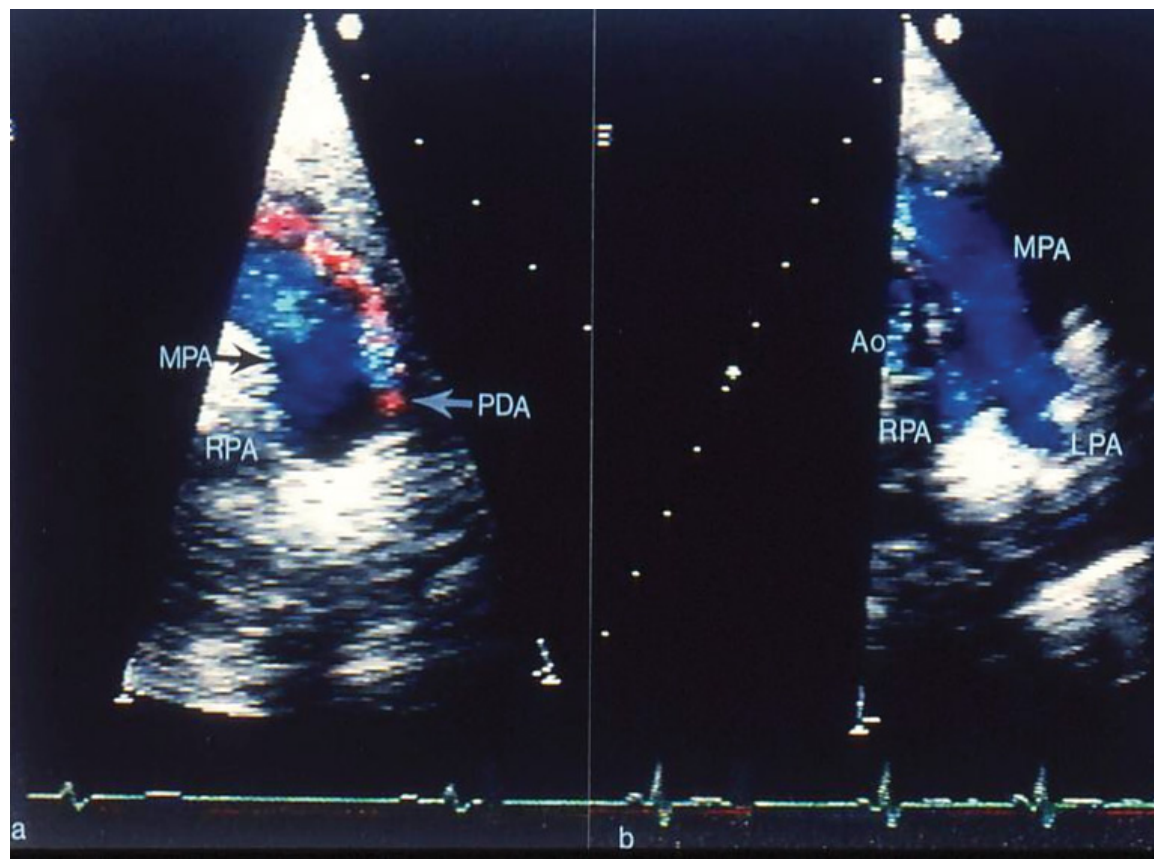

Figure 6: a) Selected video frames from two-dimensional and color Doppler echocardiographic precordial short-axis views of the main pulmonary artery (MPA) prior to and b) Following trans-catheter buttoned device occlusion of patent ductus arteriosus (PDA). Note color flow disturbance indicating a small-to-moderate-sized PDA that is no longer seen in $b$ following trans-catheter closure. Forward (blue) flow in the MPA is seen. Also, there is no evidence for obstruction in the main, left (LPA) or right (RPA) pulmonary arteries [41]. Ao: Aorta.

A review of why, when and how ASDs should be closed in adult subjects was presented with consequent recommendation for ASD occlusion at the time of presentation, irrespective of the symptomatology, provided right ventricular volume overloading is present. Special precautions are needed while closing ASDs in adults because of restrictive left ventricular filling and pulmonary hypertension in the adult patients $[29,30]$.

The management of ostium primum, sinus venosus and coronary sinus ASDs is mostly by surgical repair with rare cases amenable for percutaneous treatment $[9,10]$.

Patent foramen ovale (PFO), generally considered to be a normal variant can become the seat of right to left shunt causing paradoxical embolism resulting in cerbro-vascular accidents or transient ischemic attacks [32], cause hypoxemia as seen in platypnea-orthodeoxia syndrome $[33,34]$, and produce arterial desaturation because of right to left shunt via PFO/ASD in subjects who had prior treatment for complex congenital heart defects, including Fontan fenestrations $[35,36]$. The usefulness of buttoned device in closing these ASDs/ PFOs was reviewed and it was concluded that such is feasible, safe and effective [32-36].

After the withdrawal of the buttoned device from clinical trials, the author began the use of ASO, Cribriform device and Amplatzer PFO occluder to address all types of ASDs/PFOs.

\section{Patent Ductus Arteriosus}

At first, the pathologic and pathophysiologic features of patent ductus arteriosus (PDA) were detailed, fol- lowed by, historical aspects $[2,3,6,7,37]$ of development of percutaneous closure of PDAs. Then, indications $[38,39]$ for PDA occlusion were presented. The contributions of the author pertaining to buttoned device, Gianturco coils and Amplatzer Duct Occluder were individually discussed.

Following the initial description of the PDA buttoned device in 1990 [40,41], several modifications of the device form the original device to adjustable buttoned device, infant buttoned device, folding plug device, and trans-catheter patch were undertaken [42-46]. The immediate (Figure 6) and follow-up results of PDA occlusion with the buttoned device by the author as well as those of the US FDA-approved and international clinical trials were presented one by one [42-46], which demonstrated feasibility, safety, and effectiveness of this procedure. The results in adult subjects were similar $[44,47]$. An assessment of successive cohorts of the buttoned device indicated that the introduced alterations reduced the size of the delivery sheath so that they may be used in infants, resulted in more complete closure at the time of device implantation, and produced progressive increase in full PDA closure rates both at 24 hours and one year following device occlusion of the PDA [46].

A comparison of the available PDA closing devices as of that time indicated similar feasibility, safety, and effectiveness of all devices examined; however, these were on the basis of separate clinical trials with each of the devices and there were no randomized clinical trials $[45,48,49]$.

Gianturco coils and their deployment across the 


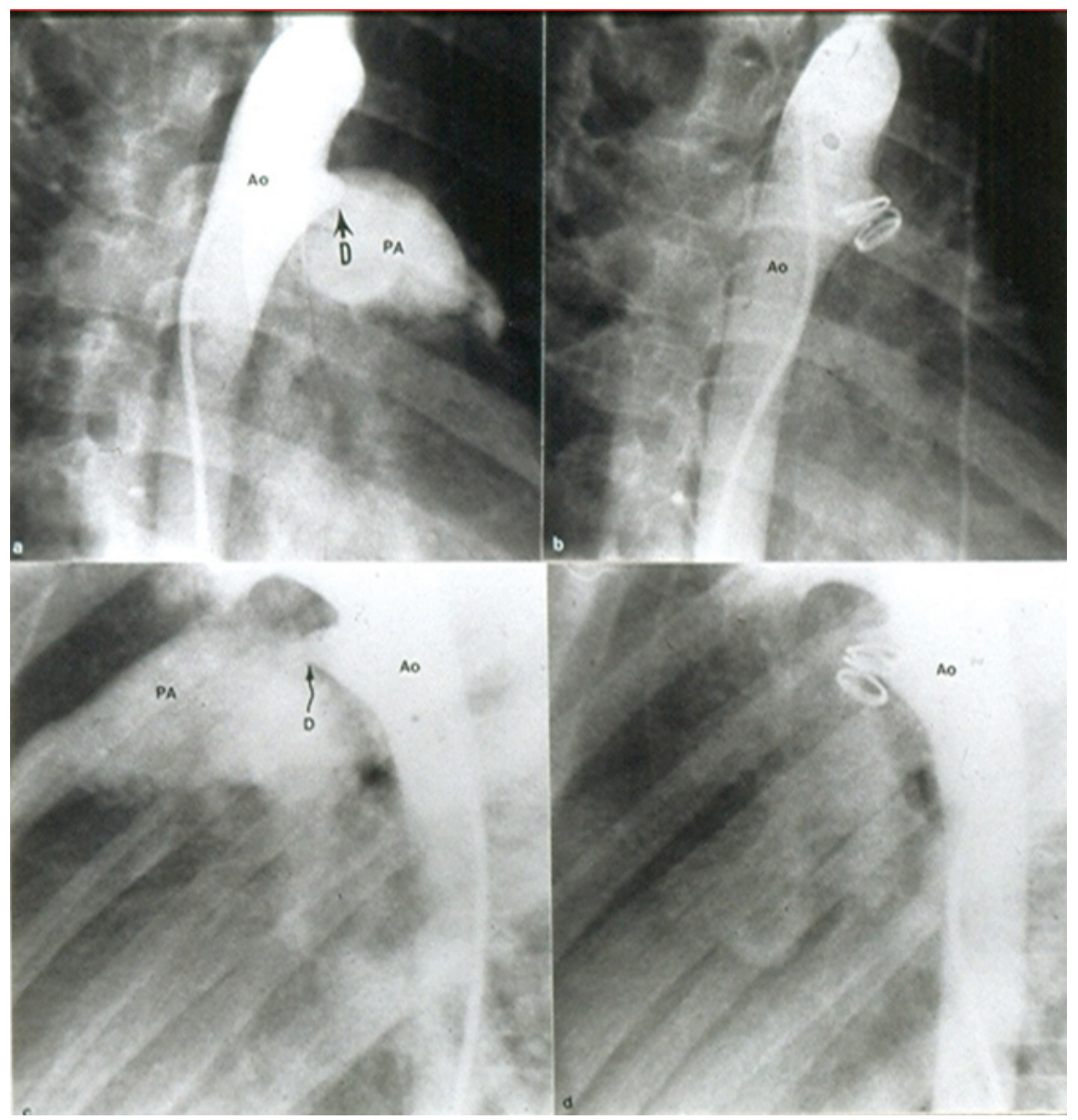

Figure 7: Selected cine frames from aortic arch angiograms in $30^{\circ}$ right anterior oblique (a and b) and straight lateral (c and $d$ ) views showing a moderate sized ductus $(D)$ before (a and $c$ ) and 15 minutes following (b and d) coil occlusion. Note complete occlusion of the ductus in $b$ and $d$ [52].

Ao: Aorta; PA: Pulmonary Artery

PDAs (Figure 7) was then described $[50,51]$ with highlighting on the utility of 5-loop coils to provide better occlusions both at the time of coil implantation and at follow-up evaluation [52,53]. Feasibility, safety, and effectiveness of occlusion of PDAs in children with right aortic arch were shown. At the same time it was emphasized that the structure of the aortic arch and ductal anatomy should be carefully defined and understood so as to make sure that no symptomatic vascular ring is present prior to embarking upon PDA closure [54].

The author's experience with Amplatzer Ductal Occluder (ADO) in closing PDA was then reviewed with the conclusion that the PDA occlusion (Figure 8) with ADO is feasible, safe and effective with infrequent complications $[55,56]$. Limited experience with ADO II and Amplatzer vascular plug was also presented [57].

After the withdrawal of the buttoned device from clinical trials, the author continued the use of Gianturco coils for occluding small PDAs and implemented the use of ADO, ADO II, and Amplatzer vascular plug to close all other vanities of PDAs $[38,58]$.

Ductal constriction spontaneously in a former premature baby was documented with the suggestion for precautions to avoid embolization and selection of appropriate-sized devices [59]. Complications seen with percutaneous closure of PDA were reviewed and methods of management were reviewed [59]. Patients who had intravascular hemolysis [60] and descending aortic obstruction following prior Gianturco-Grifka Vascular Occlusion Device (GGVOD) device occlusion of PDA [61] were presented, as well as their management. A patient who had successful concurrent percutaneous treatment of severe aortic stenosis and moderate-sized PDA was illustrated [62] and the previously reported experience with treating two or more cardiac defects concurrently with trans-catheter techniques was also reviewed [62].

Approaches for PDA closure on the basis of the shape of the PDA and minimal ductal diameter (Figure 9) were reviewed in detail $[38,50,58,63,64]$.

The author recently examined the role of echocardiographic studies in the evaluation of PDA in premature babies [65] and the utility of transcatheter closure of PDA in the preme [39].

The PDA produces a left-to-right shunt, largely proportional to the minimal ductal diameter. In premature 


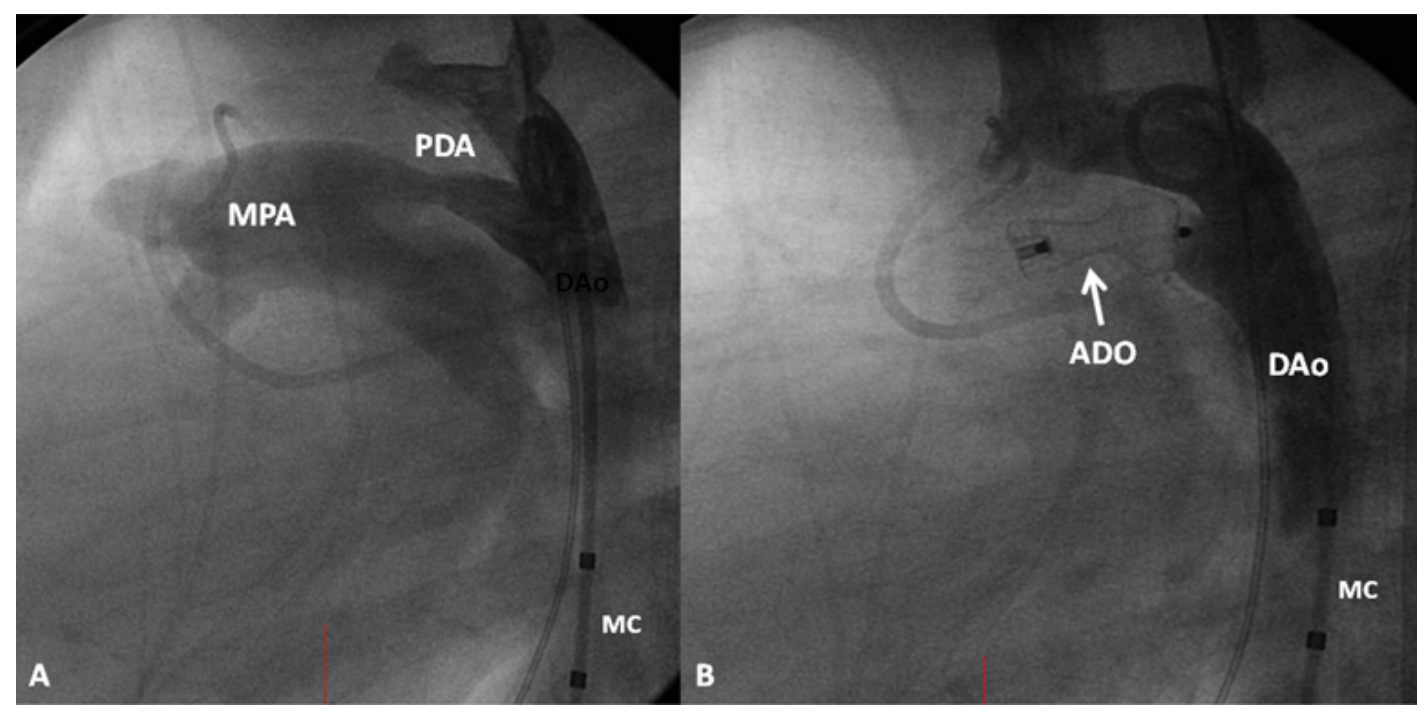

Figure 8: A) A selected cine frame from an aortic arch angiogram in lateral view, demonstrating a moderate-sized patent ductus arteriosus (PDA) opacifying the main pulmonary artery (MPA); B) Following the implantation of an Amplatzer duct occluder (ADO), no residual shunt is seen. Also, there is no descending aortic (DAo) obstruction. MC: Marker Pigtail Catheter

\begin{tabular}{|l|l|}
\hline Type & Description \\
\hline Silent PDA & $\begin{array}{l}\text { Usually less than } 1.5 \mathrm{~mm}^{*} \text { without audible } \\
\text { murmur of PDA }\end{array}$ \\
\hline Very small PDA & $\leq 1.5^{*}$; a murmur of PDA is present \\
\hline Small PDA & $1.5-3.0 \mathrm{~mm}^{*}$; a murmur of PDA is present \\
\hline Moderate PDA & $3-5 \mathrm{~mm}^{*}$; a murmur of PDA is present \\
\hline Large PDA & $>5 \mathrm{~mm}^{*}$; a murmur of PDA is present \\
\hline "minimal ductal diameters on lateral cineangiographic view. \\
PDA = patent ductus arteriosus.
\end{tabular}

Figure 9: Classification of patent ductus arteriosus (PDA) based on the size [38].

babies, such shunts cause pulmonary and cardiac compromise. Although the clinical features, chest X-ray and serum brain natriuretic peptide (BNP) levels help to identify a PDA, hemodynamically significant PDAs are best detected and quantified with the help of echo-Doppler studies. The size of the LA, LA: Ao ratio, diameter of the $\mathrm{LV}$, estimated pulmonary artery pressures, minimal ductal diameter, and Doppler flow velocity across the PDA, and descending aortic Doppler flow patterns help the clinician to identify the size of the PDA (Table 15-10 of reference [1]). A medium-to-large PDA in association with respiratory compromise calls for a diagnosis of a hemodynamically significant PDA $[1,39,65]$.

The management strategies proposed in the distant past, namely, to completely ignore the ductus, or to administer prophylactic pharmacological or surgical treatment to all premature babies, are not currently recommended. When a hemodynamically significant PDA is identified, conservative management to include fluid restriction, diuretic therapy and respiratory and other supportive measures is instituted, to provide opportunity for spontaneous PDA closure. If no improvement is observed, pharmacologic therapy with indomethacin, ibuprofen or paracetamol should be started. Ibuprofen is preferred by some because of its lower renal toxicity. The failure of two courses of pharmacologic therapy requires the consideration of surgical (conventional, bedside or VATS) or percutaneous closure of the PDA, depending upon the institutional expertise $[1,39]$.

Transcatheter PDA closure in preterm infants has not been frequently performed in the past because of introducer size constraints and the potential for device dislodgement. More recently, some of these issues were resolved. The initial experience of PDA occlusion in premature infants was documented in single case reports; subsequently, case series ranging from 10 to 32 babies was reported [39]. A recent review suggested that the Micro Vascular Plug, ADOII-AS, and Amplatzer Vascular 
Plug II are more commonly used devices for percutaneous occlusion of PDAs in the premature. Percutaneous closure of PDAs in premature infants was introduced at our institution in late 2015. In the first 18 months, 34 premature infants weighing less than 3 kilograms at the time of the procedure underwent device closure [39]. All the PDA occlusions were performed using either the Medtronic Micro Vascular Plug $(n=29)$ or the Amplatzer Vascular Plug II $(n=5)$. These devices were selected mostly due to the feasibility of implanting the devices entirely within the ductus arteriosus, with no protruding disk within the descending aorta or pulmonary artery. The Micro Vascular Plug has the advantage of being delivered via a \#4 French catheter, or even a \#3 French catheter when using the smaller sized devices. However, it is difficult to visualize by fluoroscopy. The Amplatzer Vascular Plug II requires a stiffer delivery sheath that is more prone to cause hemodynamic instability by propping open the tricuspid and pulmonary valves. Complete closure was achieved in all patients. There were no procedural complications, and no escalation of respiratory management. One transcatheter device embolized 9 days after deployment and was successfully retrieved, and a larger device was then implanted. There were no long-term sequelae, and the patient was stable at the time of device retrieval. Patients were extubated in a median of 3.5 days (0-29 days) and were weaned off all respiratory support and oxygen in a median of 16 days ( $0-153$ days). Of the 24 patients discharged at the time of this report, two were discharged on oxygen therapy. An example of a follow-up echo-Doppler study is shown in Figure 10. More than 50 additional cases have been performed at our institution since the last report [1,39] with similar results.

Change of the murmur of PDA with postural variation in three children was demonstrated; the disappearance of PDA murmur in upright position was ascribed to kinking of the ductus. The utility of auscultation in both supine and upright positions was emphasized [66]. Information to support lack of reliability of echocardiographic estimation of angiographic minimal ductal diameter was presented $[67,68]$. The utility of echocardiographic studies in the assessment of PDA in the premature babies was reviewed [65] as was their diagnosis and management [39]. Earlier data of the author in demonstrating effectiveness of $\mathrm{PGE}_{1}$ infusion to improve $\mathrm{O}_{2}$ saturations in neonates with cyanotic heart defects and pulmonary oligemia (Figure 11) [69] was also presented.

\section{Ventricular and Atrio-Venricular Septal Defects}

Initially, the pathologic, pathophysiologic, clinical, echocardiogrphic, and angiographic features of ventricular septal defects (VSDs) were examined. This is followed by description of historical aspects of development of percutaneous closure of VSDs $[2,6,7,70,71]$ and indications (moderate to large VSDs with enlarged left atrium and left ventricle and/or elevated pulmonary artery pressure and a Qp:Qs greater than 2:1) for VSD closure [8,71-73]. VSD occlusion with buttoned and Amplatzer devices were separately reviewed.

The VSD buttoned device is similar to buttoned device used to close ASDs and PDAs [17,74-77]. Furthermore, self-adjustable [75,77] and wireless devices (detachable balloon device and trans-catheter patch) [77] were also designed for percutaneous VSD occlusion. Based on immediate and follow-up results of buttoned device occlusion of VSDs [74-77], it was concluded that VSD occlusion with different types of buttoned devices is feasible; the most commonly used method is trans-venous route, and the trans-arterial route is the easiest of all the methods to deploy the devices across the VSD [74-77]. Trans-catheter patches appear to be promising to address VSDs with small or no septal rim [77].

The data on Amplatzer Muscular VSD Occluder was

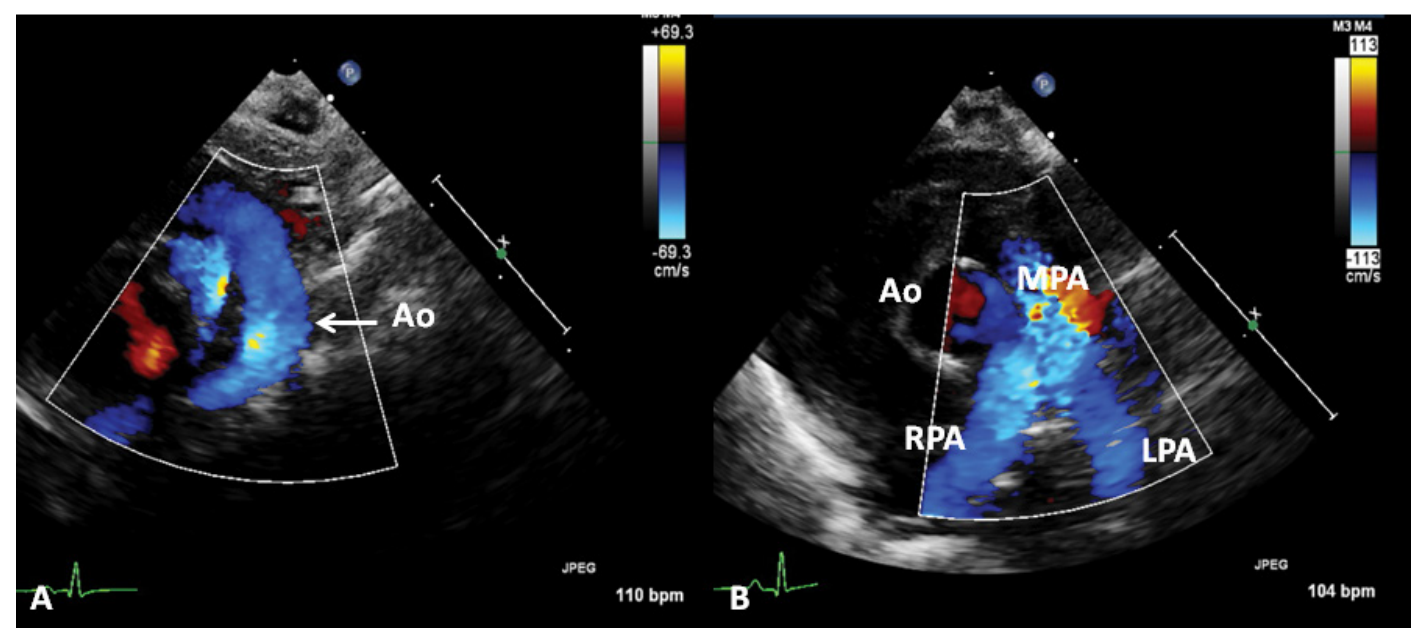

Figure 10: A) Selected echocardiographic frames from suprasternal notch and B) parasternal short axis views, demonstrating laminar flow in the aorta (Ao) $(A)$ and $B$ ) branch pulmonary arteries in a premature baby who underwent percutaneous occlusion of the ductus with a Medtronic Micro Vascular Plug a month earlier [38].

MPA: Main Pulmonary Artery; LPA: Left Pulmonary Artery; RPA: Right Pulmonary Artery 


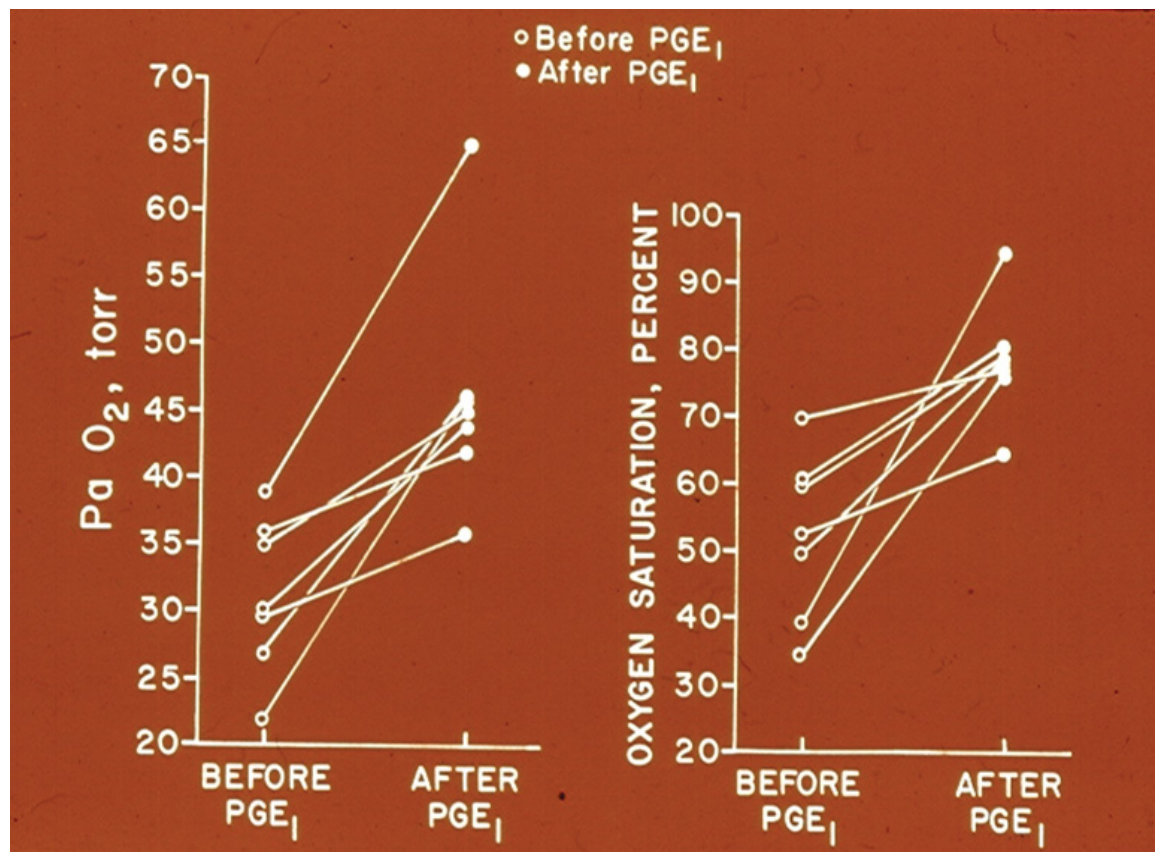

Figure 11: Graphs demonstrating the effect of prostaglandin $E_{1}\left(P G E_{1}\right)$ infusion on the systemic arterial tension $\left(\mathrm{PaO}_{2}\right)$ (left panel) and oxygen saturation (right panel) in seven neonates with cyanotic congenital heart disease and ductal dependent pulmonary circulation. A significant increase in the $\mathrm{PaO}_{2}$ and $\mathrm{O}_{2}$ saturation was seen in each case. The open circles represent the values prior to $\mathrm{PGE}_{1}$ and the closed circles represent the values following $\mathrm{PGE}_{1}$ infusion [69].

scrutinized and it was concluded that percutaneous VSD closure is feasible, safe and effective in the majority of patients $[71,78]$. Hybrid approach for occlusion of large muscular VSDs in small infants $[71,79,80]$ and surgery for preimembranous VSDs [71], supracristal VSDs [71] and VSDs with aortic insufficiency caused by aortic valve prolapsed $[71,81,82]$ appear appropriate. If percutaneous and hybrid approaches are not possible, specifically in small babies with the Swiss-cheese type of VSDs, banding of the pulmonary artery first and later followed by VSD closure later was recommended [71]. Intervention in a timely manner to prevent pulmonary vascular obstructive disease was stressed [71]. Prudence against closing small VSDs was suggested and the responsibility of pediatricians and the general pediatric cardiologists in avoiding unnecessary closure of small VSDs was emphasized [71].

Most of the devices used for VSD occlusion $[2,6,7,70,71]$ including the Amplatzer muscular VSD Occluder are double-disc devices and consequently require septal rims to hold the device in place. Because of that reason, they can be used only in occluding muscular VSDs and perimembranous defects with an adequate-sized aortic rim. It is not feasible to close the more common perimembranous VSDs because of lack of aortic rim and proximity of the aortic valve to the VSD. To address these challenges, the device was redesigned [83] so that the aortic end of the left ventricular disc is made shorter $(0.5 \mathrm{~mm})$ while the other end is designed to be longer $(5.5 \mathrm{~mm}$ ) (Figure 16-24 of reference [1]). The lower pole of the left ventricular disc was impregnated with a platinum marker in order to aid ap- propriate device positioning during deployment of the device. This redesigned device was named Amplatzer Membranous VSD Occluder (St. Jude Medical, Inc.). The results of Amplatzer Membranous VSD Occluder to close membranous VSDs, including the US FDA-approved US clinical trials [84] was reviewed elsewhere [1,71,84], and were generally considered acceptable. Apart from the usual complications seen with complex procedures, complete heart block (as detailed in our review [85]) developed in a significant percentage of patients both immediately after and during follow-up after implantation of Amplatzer Membranous VSD occluders. The waist connecting the discs of the most double-disc devices is placed within the VSD, is smaller than the VSD, and does not stretch the defect. The mechanism by which the defect is closed is by stop-flow by the discs on either side of the VSD. But, the Amplatzer Membranous VSD Occluder "stents" the VSD and, with time, stretches the defect since the device size is commonly larger than the diameter of the VSD. Because the conduction system is located along the rims of the VSD, the device exerts pressure on the conduction system [85]. This is likely to be the mechanism for development of heart block and conduction abnormalities, as reviewed elsewhere [85]. The prevalence of complete heart block varied between 1 and $22 \%$ and many of them required pacemaker implantation [85]. This is in contradistinction to $1 \%$ incidence of heart block after surgical closure of VSD $[71,85]$. Consequently, it is difficult to justify the use of membranous VSD Occluder to close the VSDs. Indeed, the device did not receive FDA approval.

Additional items with regard to VSDs such as value of 
auscultation in the assessment of heart defects in children [86], occurrence of pulmonary edema while testing pulmonary vascular reactivity [87], onset of bacterial endocarditis in small VSDs [88], and total percutaneous treatment of tetralogy of Fallot [89] were also reviewed.

Lastly, the treatment of AVSDs was reviewed [71]; the AVSDs can't be addressed by trans-catheter methodology and need surgical therapy. The treatment involves medical management of congestive heart failure (CHF) initially and then, surgical correction with closure of atrial and ventricular septal defects along with repair and reconstruction of atrioventricular valves. Pul- monary artery banding may be performed in infants weighing less than $5 \mathrm{Kg}$ and in patients with significant co-morbid conditions followed by complete correction at a later time [71]. The management of unbalanced AVSDs is more complicated and usually requires staged single ventricle palliation; however, accomplishing a two-ventricle repair may be a better option in babies with suitable anatomy $[71,90]$.

\section{Miscellaneous Trans-Catheter Occlusions}

At first, embolic materials utilized for occlusion, the technique of closure, the mechanism of occlusion of the shunt lesions, and complications seen with the
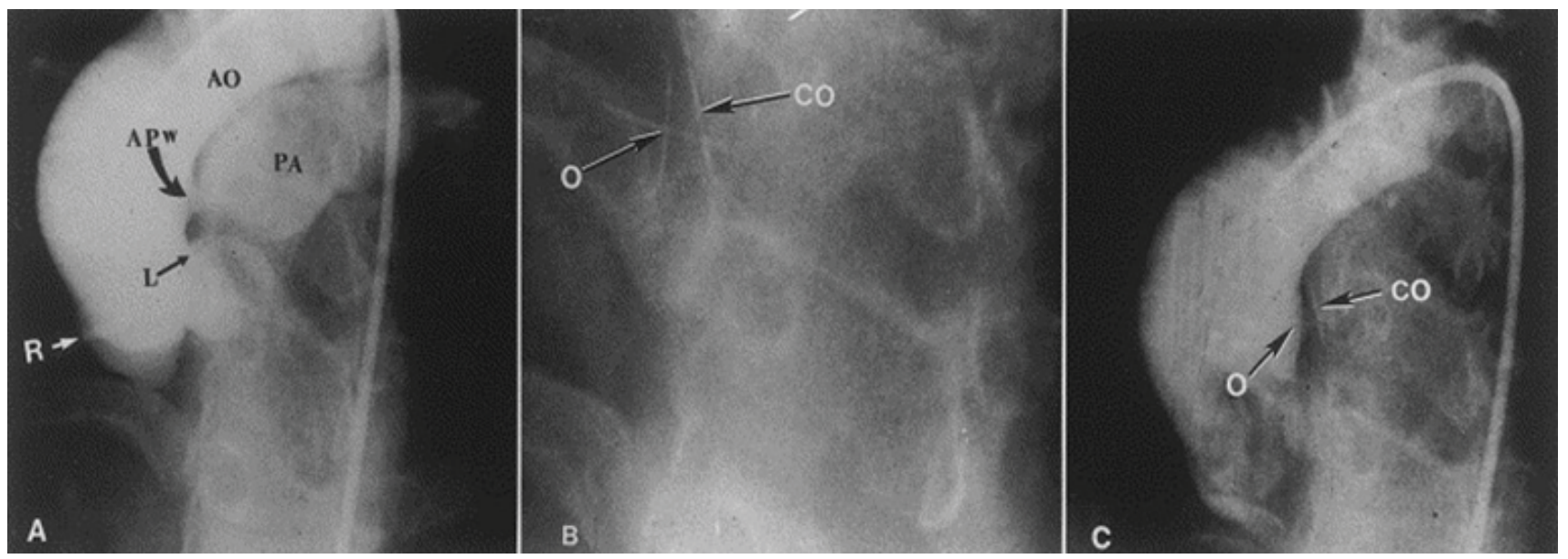

Figure 12: A) Selected frame from a cineaortogram in the left anterior oblique projection, demonstrating the location, size, and shape of the aortopulmonary window (APW). There is dense filling of the pulmonary artery (PA). The distance between the defect and the left coronary artery $(L)$ is foreshortened in this view but is outlined better on the lateral projection (not included); B) The occluder (O) and counter occluder ( $\mathrm{CO}$ ) of the buttoned device are shown after their buttoning across the defect; C) Repeat aortic root angiogram in the same view as in A after the buttoned device placement, showing minimal, if any, filling of the pulmonary artery. AO: Aorta; R: Right Coronary Artery [93].

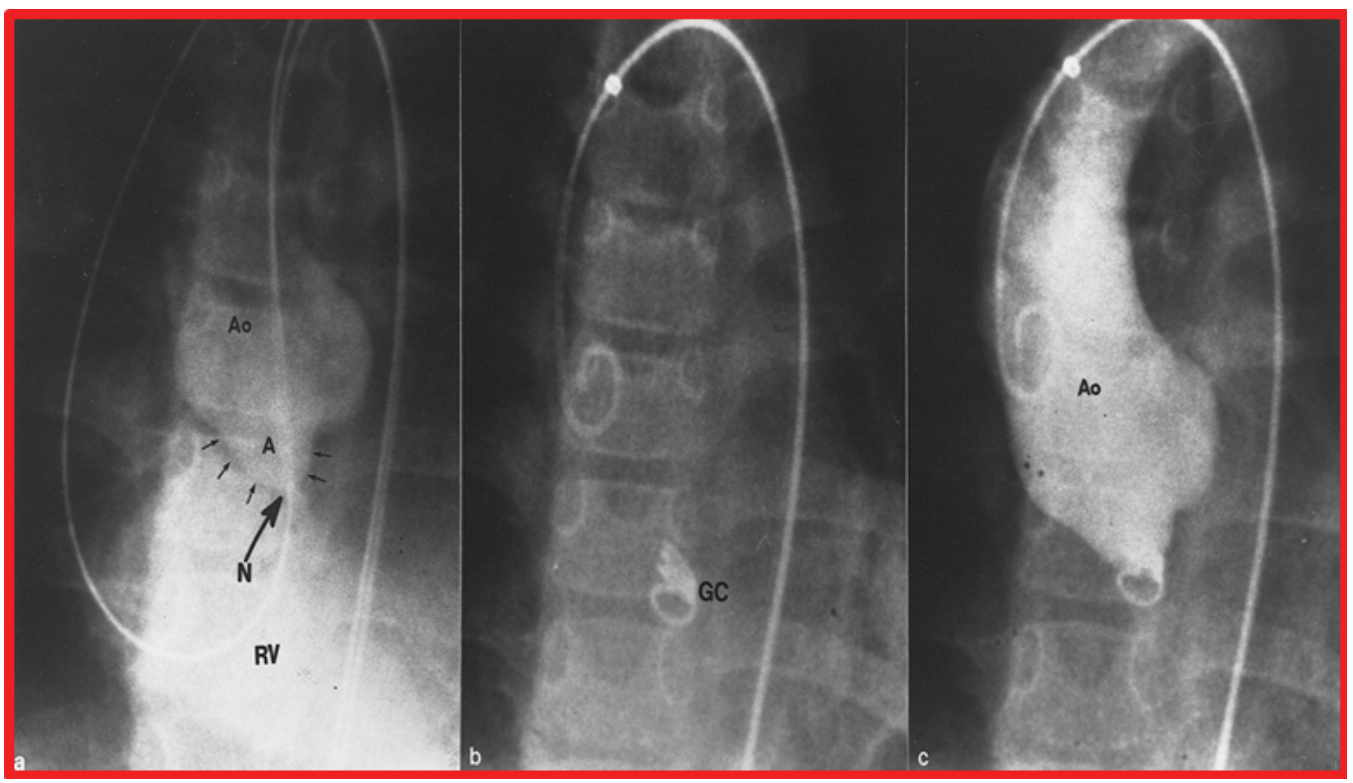

Figure 13: a) Selected cine frame from an aortic (Ao) root cineangiogram in anterio-posterior view, demonstrating a ruptured sinus of Valsalva aneurysm (A) (marked with small arrows) opacifying the right ventricle (RV). The neck (N) of the ruptured aneurysm into the RV is marked with a large arrow; b) Selected cine frame from an Ao cineradiogram, showing a Gianturco coil (GC); c) Following the GC placement, the fistulous connection (N) is almost completely occluded. b \& c. Note that one loop of the GC is in the RV while the remaining loops are within the aneurysm [94]. 
procedure [91,92] were discussed. Then, a description of prevalence of the abnormal vascular connection, embolic materials used in the past, results of the occlusion procedure [91,92] and illustrations from the author's personal experience of aorto-pulmonary window (Figure 12) [93], ruptured sinus of Valsalva aneurysm (Figure 13) [94], pulmonary arteriovenous fistulae [57,91] aortopulmonary collateral vessels [57,91,92], coronary arteriovenous fistulae (Figure 14) [57,91,92], aorto-pulmonary surgical shunts [91,92], vascular supply of sequestered pulmonary segments $[57,92]$, collateral vessels that develop after bi-directional Glenn and Fontan procedures [92,95], Fontan fenestrations (Figure 15) [95], residual defects after Fontan, and other lesions $[57,91,92,95]$ were shown.

Occlusion of superfluous vascular connections is feasible and can be carried out with various types of embolic materials $[91,92]$. Past practice with embolization of the target vessel with Gianturco coils is relatively simple and effective in the majority of clinical scenarios, particularly if the target vessel to be occluded is small when the procedure can be undertaken with the use of small diameter catheters. However, if the target vessels are large, ASD and PDA occluding devices and Amplatzer vascular plugs (AVPs) are necessary [57,91,92]. A full understanding of the vascular anatomy, pathophysiologic effects of embolic occlusion of the target vessel, and possible complications is critical prior to undertaking the embolization procedure $[91,92]$. In addition, the accessibility of appropriate catheter/guide wire systems and embolic material in the catheterization laboratory is crucial prior to performing trans-catheter occlusion. It is commonly thought that percutaneous techniques have advantages when compared with the conventional surgical methods. In the author's view, percutaneous method should be the first choice in the treatment

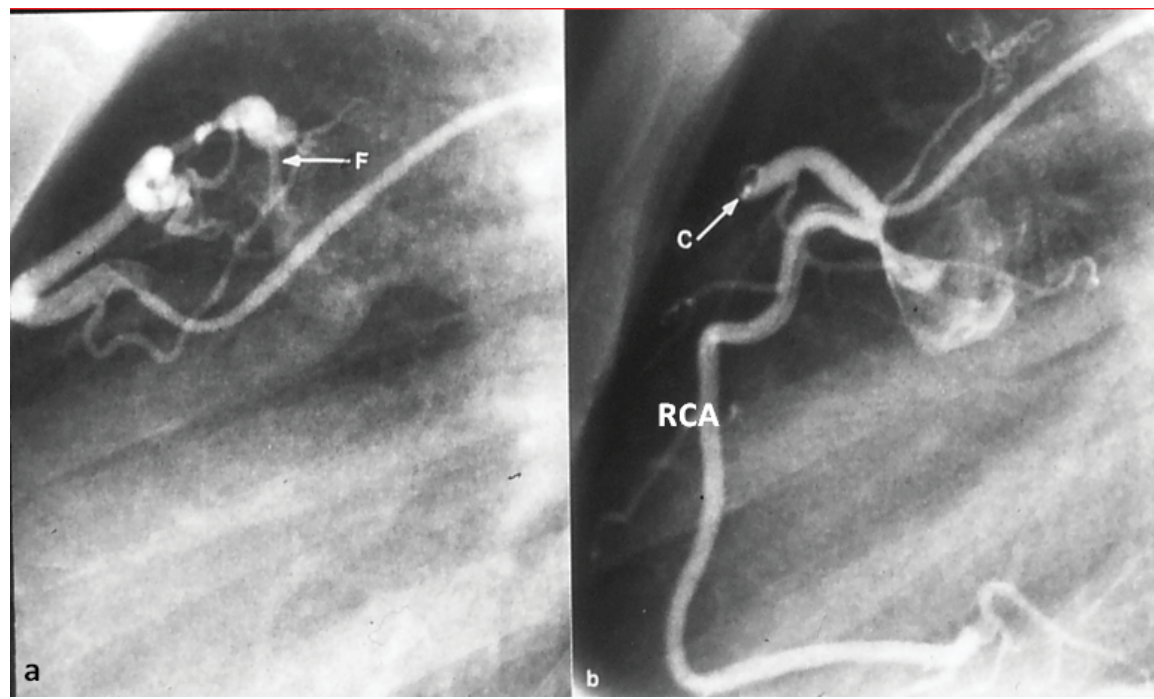

Figure 14: a) Selected cine frame from a right coronary arteriogram with the catheter tip in the feeding vessel, showing a coronary arteriovenous fistula (F); b) After coil (C) occlusion, the $F$ is no longer visualized. The right coronary artery (RCA) is opacified in a normal fashion [91].

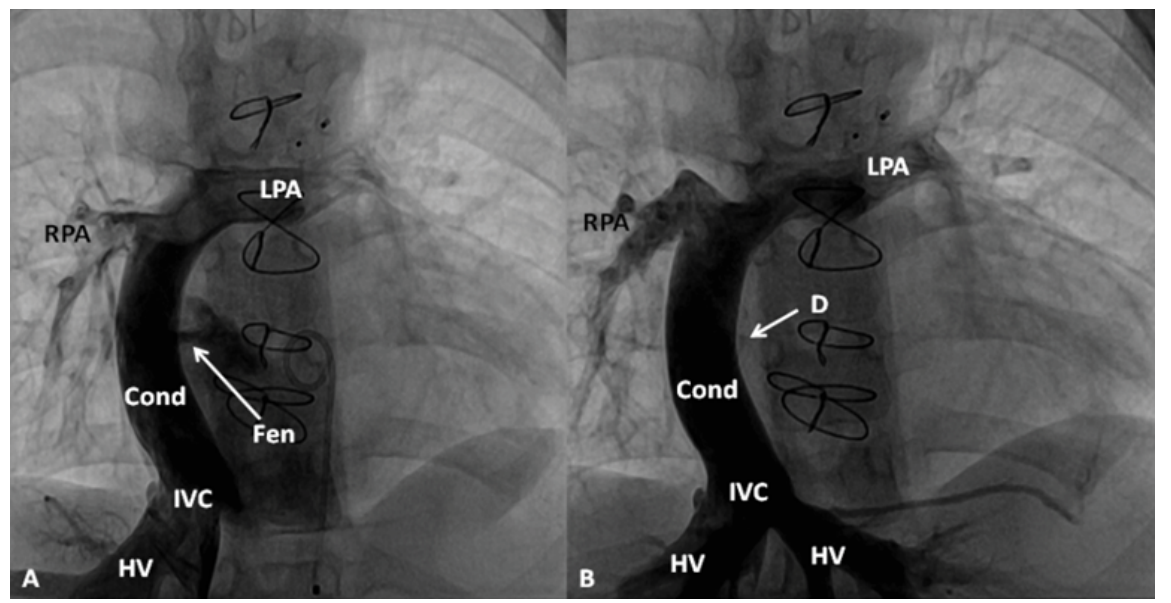

Figure 15: A) Selected cineangiographic frame in antero-posterior view, demonstrating a Fontan conduit (Cond) diverting the inferior vena caval (IVC) flow into the right (RPA) and left (LPA) pulmonary arteries via a non-valve Cond. Note the fenestration (Fen), arrow in A; B) The Fen is closed with an Amplatzer Septal Occluder device (D) (arrow) without any residual shunt. HV, hepatic veins [95]. 


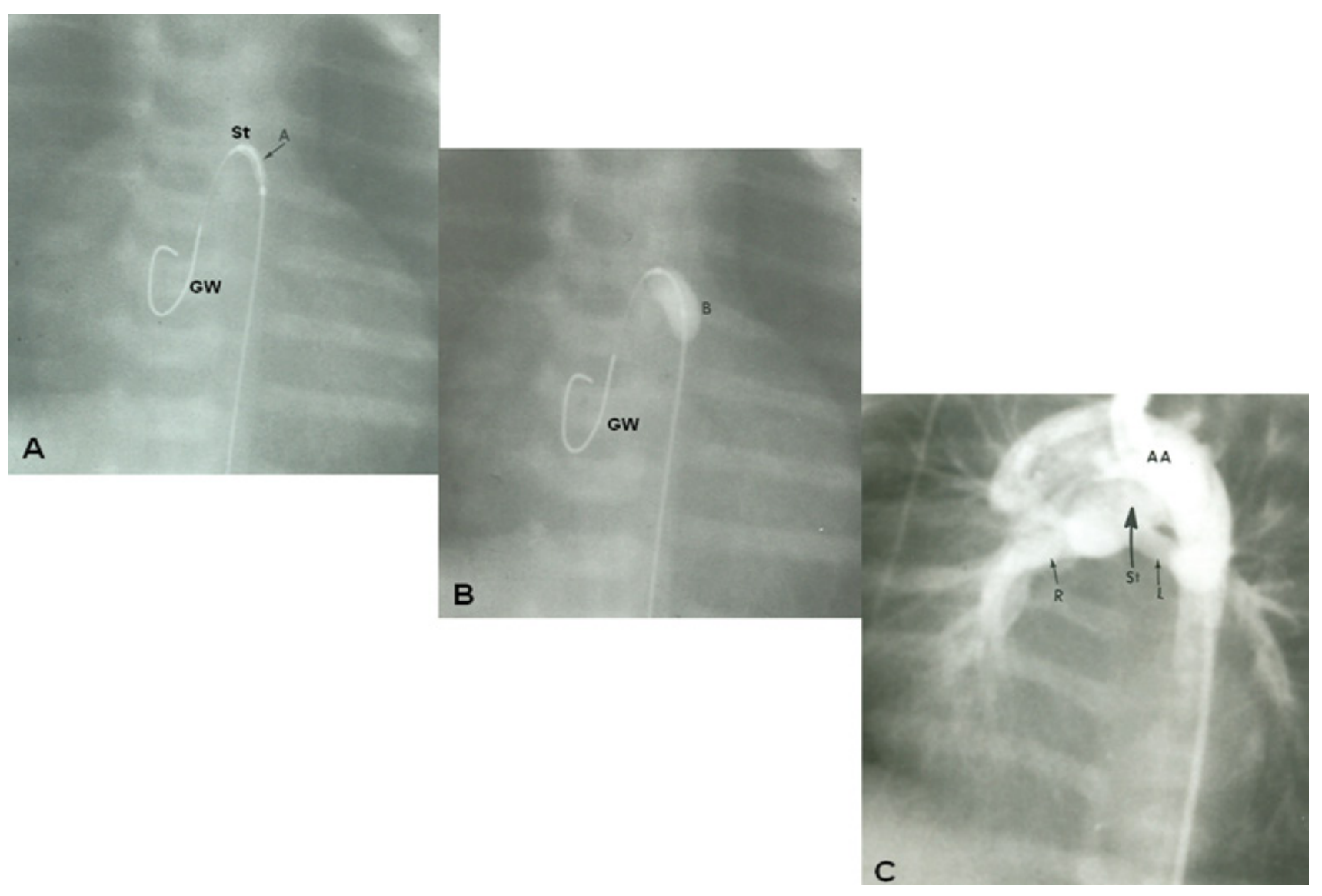

Figure 16: A) Selected cine frame demonstrating the position of a guide wire which was advanced from the aorta into the main pulmonary artery (via the ductus arteriosus) and from there into the right ventricle. The balloon/stent (St) assembly was then positioned within the ductus. The arrow demarcates the articulation (A) within the stent; B) The balloon carrying the stent is inflated within the ductus; $C$ ) An aortic arch (AA) angiographic frame shows the stented ductus (St) and good opacification the right $(R)$ and left $(L)$ pulmonary arteries [116].

of these anomalous vascular connections [91,92]. Based on this review, the conclusion was that occlusion of superfluous and abnormal vascular connections is feasible with percutaneous techniques and such methods should be the initial option in the management of these anomalous vascular connections [91,92].

\section{Stents}

At first, historical aspects, types of stents used, and the technique of stent implantation were detailed [96100]. The original contributions of the author were use of a coronary stent to keep the ductus open (Figure 16) in the management of an infant with pulmonary atresia with intact ventricular septum [101], utilizing flexible bridge stents in relieving vascular obstructive lesions [102], re-canalizing occluded/narrowed Blalock-Taussig (Figure 17) and Sano shunts [103], and investigating advantages of flexible over rigid type of stents in stent therapy in children [104].

In addition, a number reviews and editorials pertaining to stents, published by the author, were reviewed and these include their usefulness in the treatment of branch pulmonary artery stenosis (Figure 18) $[96,100,102,105]$, coarctation of the aorta (Figures 19) $[96,100,102]$, obstructed right ventricular outflow conduits (Figures 20) $[100,102]$ native right ventricular outflow obstructions in tetralogy of Fallot $[100,106]$, occluded/obstructed surgical shunts $[103,105]$, systemic venous and pulmonary venous stenoses $[100,102]$, and other sites. Future directions with regard to the use of stents in growing children $[107,108]$ were also discussed.

\section{Neonatal Catheter Interventions}

Even though Rashkind's balloon atrial septostomy has been utilized since mid-1960s, percutaneous techniques to address other CHD in children was not available until Kan and her associates extended the techniques of Dotter and Gruntzig and their colleagues to treat children in the early 1980s. Soon thereafter, these techniques were applied to manage neonates with CHD.

In several cardiac defects a wide open inter-atrial defect is beneficial. However, the PFO closes spontaneously which results in poor mixing (in TGA) and/or produces obstruction to systemic (tricuspid or pulmonary atresia) or pulmonary (mitral atresia or HLHS) venous return. In such situations, the PFO may be enlarged by trans-catheter methods such as balloon septostomy, blade septostomy, static dilatation of the atrial septum, septal perforation and stent implantation, as deemed 


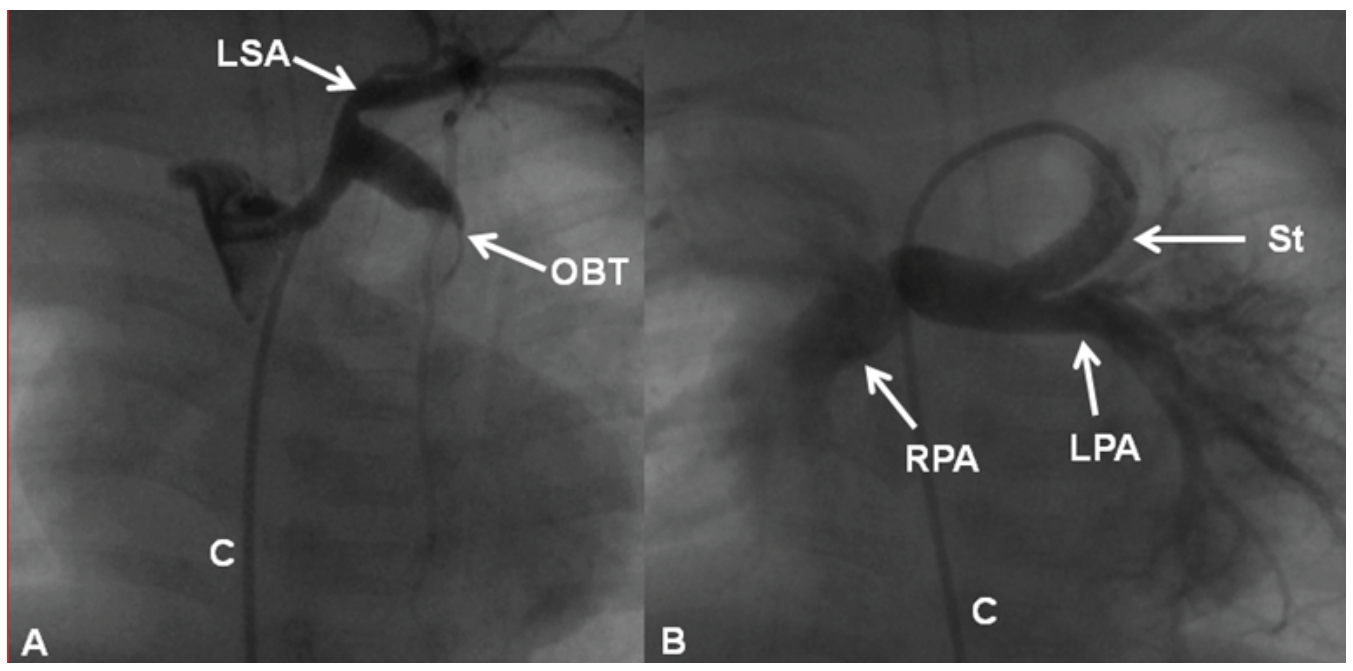

Figure 17: A) Selected cine frames demonstrating an obstructed (clotted) Blalock-Taussig (OBT) shunt prior to and B) following successful recanalization by stent implantation. The stent was implanted after unsuccessful recanalization attempts by mechanical thrombolysis with guide wires, catheters and balloon angioplasty (not shown). Note the complete opening of the modified Blalock-Taussig shunt (B) with prompt opacification of the right (RPA) and left (LPA) pulmonary arteries. C: Catheter; LSA: Left Subclavian Artery [102].

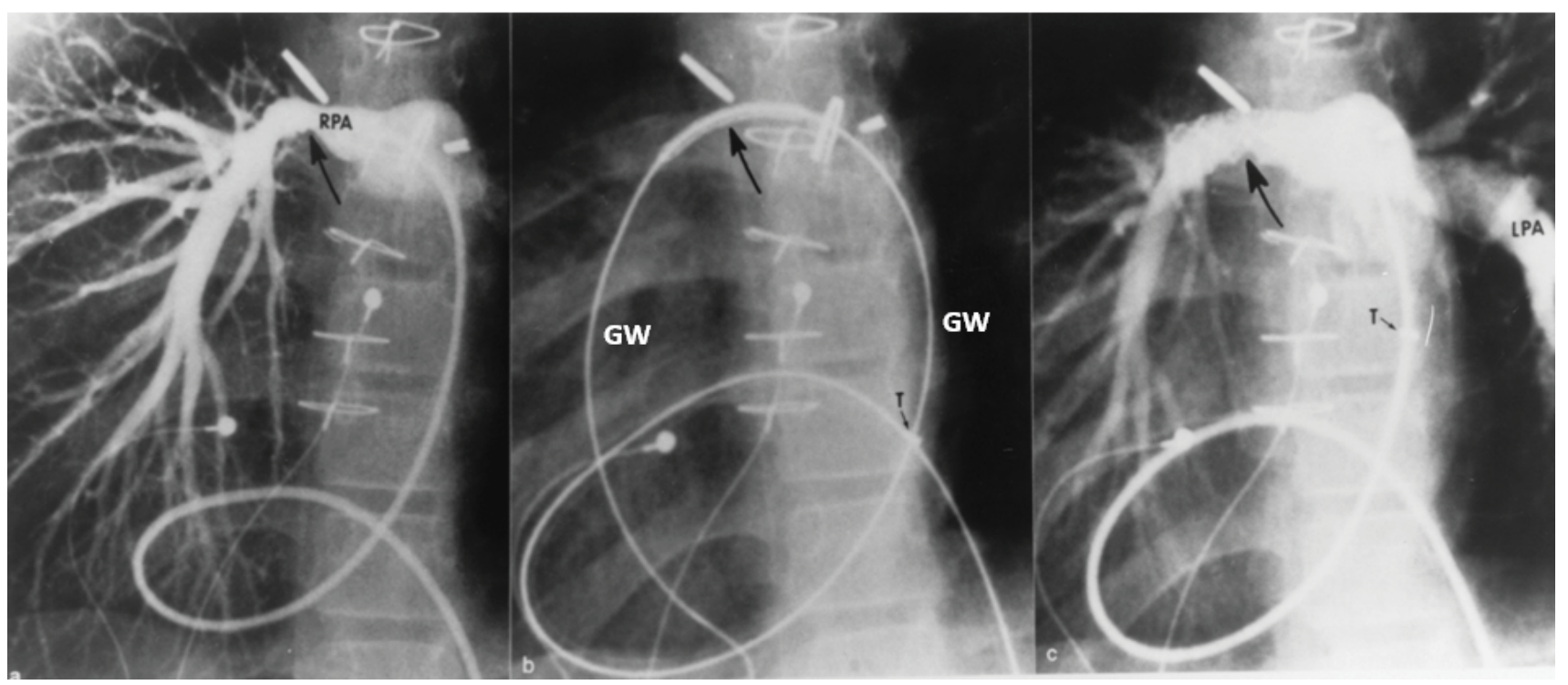

Figure 18: a) Selected cine frame from a $30^{\circ}$ right anterior oblique view, demonstrating a narrowed right pulmonary artery (RPA) (arrow); b) The position of the stent before implantation (large arrow), and c) The improved size of the pulmonary artery after stent deployment. Note the tortuous course of the catheter in a patient with dextrocardia and morphologic left ventricle to pulmonary artery conduit (not shown). The position of the tip ( $T$ ) of the long blue Cook sheath is shown. Because of its length $(65 \mathrm{~cm})$, the sheath could not be advanced any further, but the stent catheter could easily be maneuvered across the stenotic right pulmonary artery over the guide wire (GW). LPA: Left Pulmonary Artery [102].

suitable for clinical scenario at hand [106,109-111]. The choice of the procedure used is mostly dependent on the anatomy of the atrial septum and the size of the left atrium. In the most of the neonates, the catheter-based septostomy procedures are helpful in creating a suitable sized atrial defect. Infrequently, surgical septectomy may be needed [106,109-111].

Critical stenosis of the pulmonary and aortic valves in the newborn are successfully addressed with balloon valvuloplasty. Less severe obstructions may be treated past the neonatal period. While coarctation of the aorta may be successfully managed with balloon dilatation in the neonate, because of common recurrence of obstruction, balloon angioplasty is not therapy of choice in the neonate; instead surgery is preferred at this time. Nonetheless, in special circumstances balloon angioplasty is of value to the neonate. However, balloon angioplasty is the treatment of choice for post-surgical aortic recoarctations, although the need for such intervention in the neonate is rare. Pulmonary valve stenosis in association with complex cyanotic $\mathrm{CHD}$, resulting in hypoxemia can be effectively treated with balloon valvuloplasty; but, such procedure is utilized in highly selected infants [106,111-117]. 


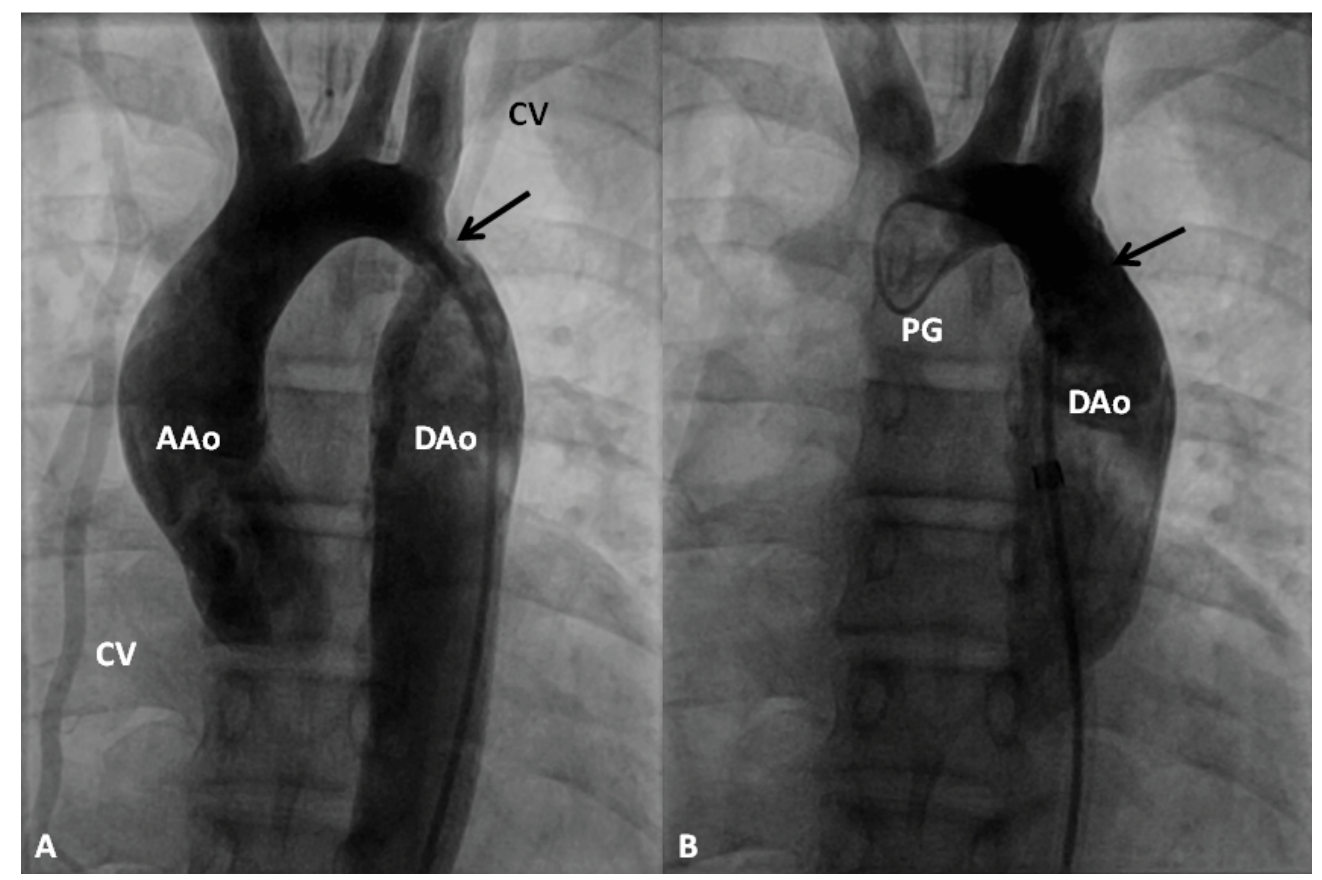

Figure 19: Selected cine frames from an ascending aortic (AAo) cineangiogram in $20^{\circ}$ left anterior oblique projection, demonstrating severe discrete coarctation (arrow in A). Following stent implantation (B), the site of coarctation is wide open without any residual gradient on pressure pullback (not shown). The collateral vessels (CV) seen in $A$ are no longer seen in B after stent implantation [99].

DAo: Descending Aorta; PG: Pigtail Catheter

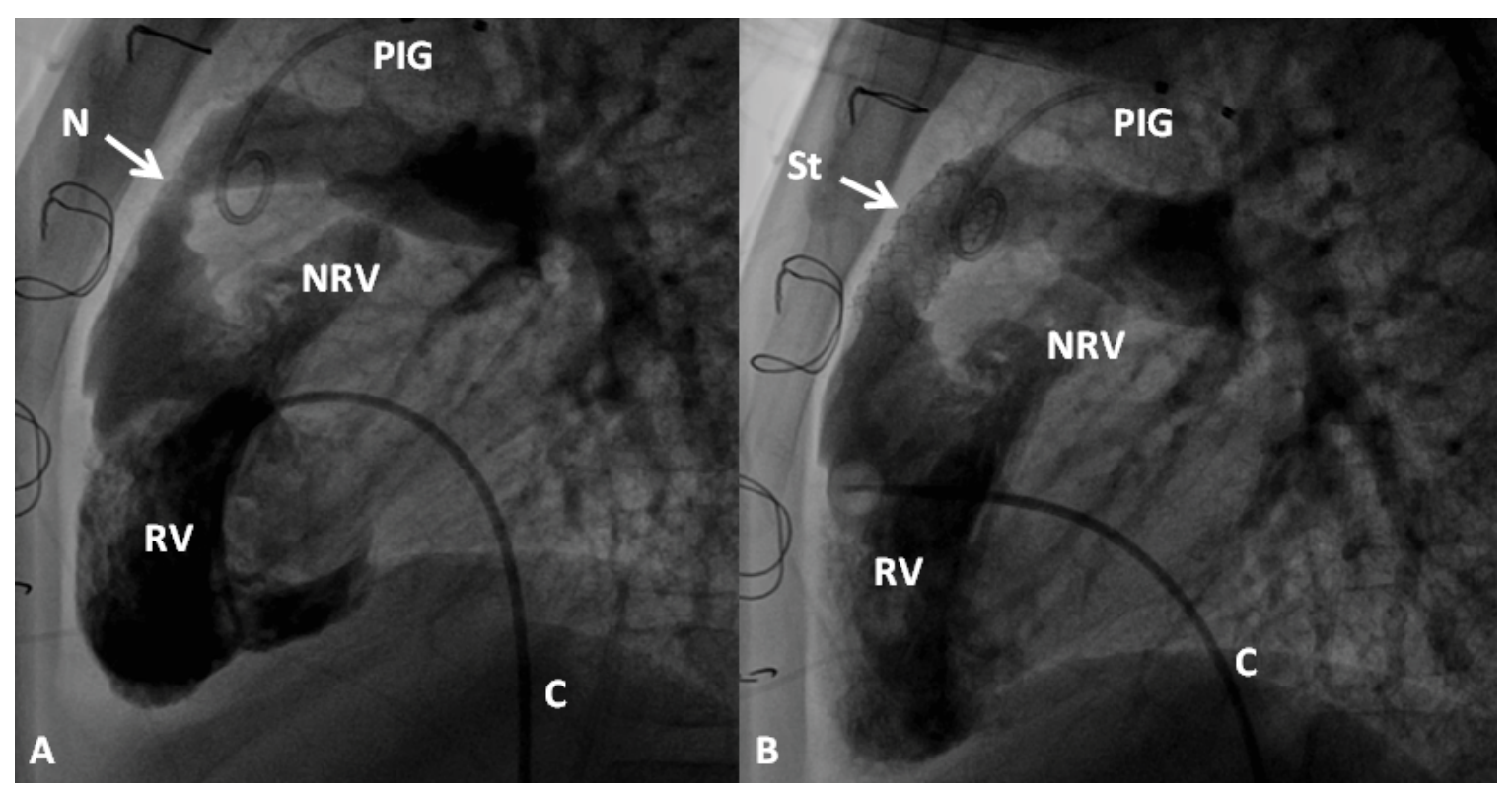

Figure 20: Selected cineangiographic frames from lateral view, demonstrating the effect of stent (St) deployment across the narrowed $(\mathrm{N})$ right ventricular (RV) outflow tract (arrow). The narrowed site (A) and RV cineangiogram after St implantation (B) show the enlargement of the stenotic site. On pressure pullback (not shown), there was an almost complete abolition of the systolic pressure gradient across this region. Blindly ending native RV outflow tracts (NRV) are also shown in both A and B. C, catheter; PIG, pigtail catheter in the aorta [99].

Radiofrequency perforation of atretic pulmonary valve (Figure 21) for neonates with pulmonary atresia with intact ventricular septum (IVS), percutaneous occlusion of defects or vessels causing CHF in neonates, and stents to expand narrowed blood vessels or to maintain an open ductus arteriosus or occluded/stenosed shunts are trans-catheter treatment approaches that comple- ment other medical and surgical management strategies [106,118-120].

The above mentioned procedures and their results were reviewed. The method selected for treatment of a particular neonate should be a technique that is most likely to provide the best possible outcome $[106,109-120]$. 


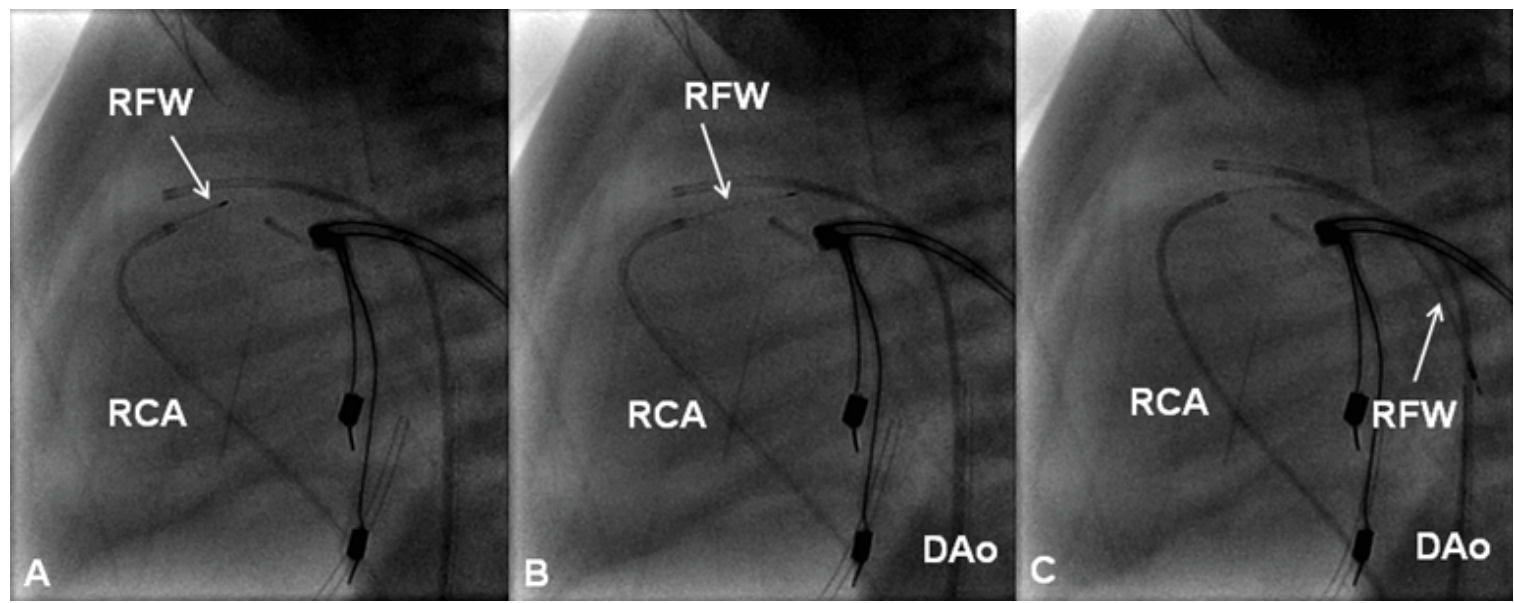

Figure 21: Selected cine frames in straight lateral views showing the radiofrequency wire (RFW) (thin arrows) being progressively advanced from the right coronary artery (RCA) catheter into the main pulmonary artery $(A \& B)$. From there it was further advanced into the descending aorta (DAo) [105].

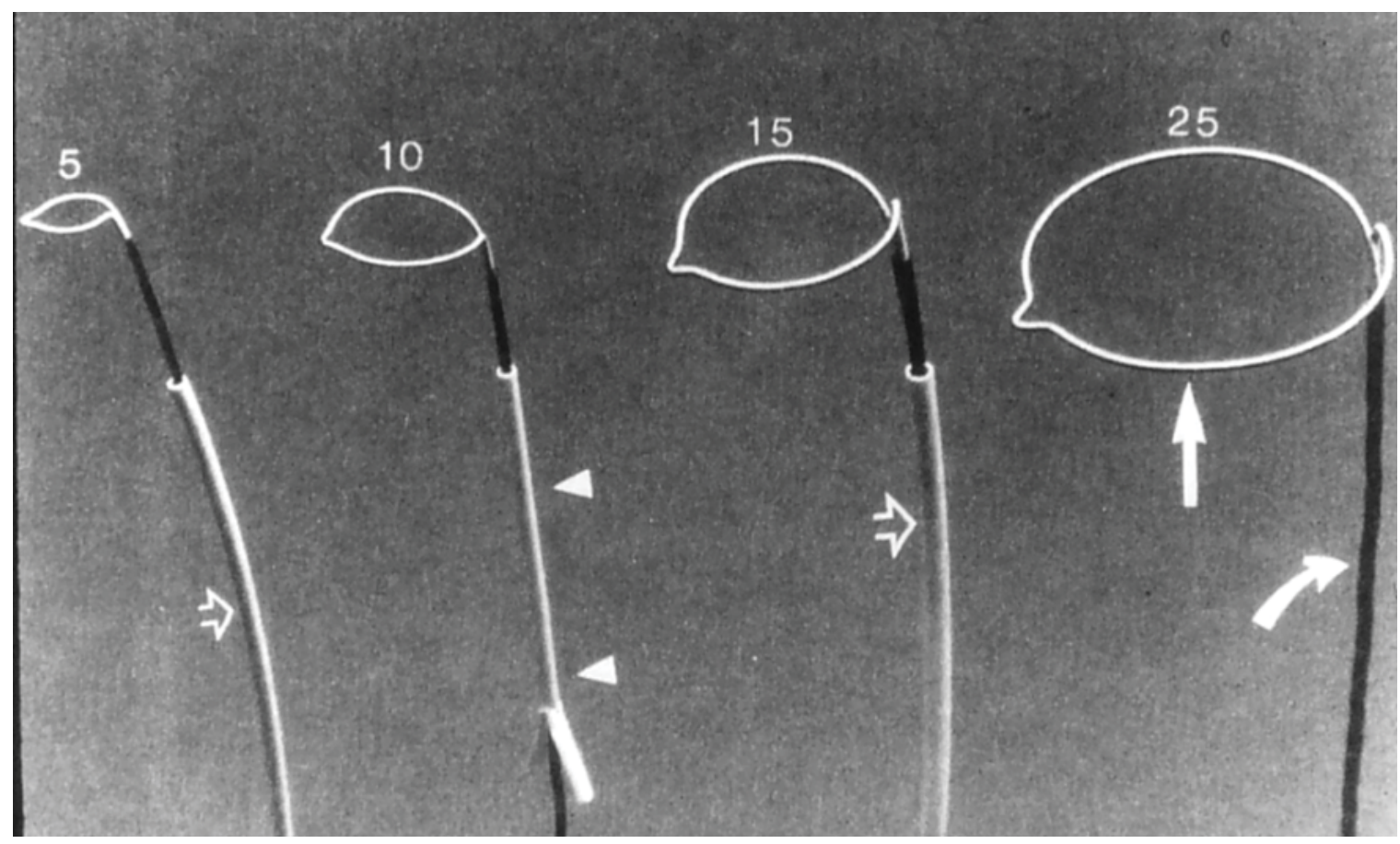

Figure 22: Photographs of gooseneck snares of different sizes (5, 10, 15 and 25 mm) (Microvena) [117].

\section{Transcatheter Retrieval of Intra-Cardiac/ Vascular Foreign Bodies}

An examination of trans-catheter retrieval of intravascular/intracardiac foreign bodies was undertaken in a chapter in the author's book in 1993 [121]. Since the first introduction by Myers in 1945 [122] of indwelling intravascular catheters, these catheters have been used widely. Because of widespread use of polyethylene catheters in critically ill patients, both for monitoring and for fluid administration, inadvertent embolization of these catheters into the cardiovascular system has increased and constitutes the single leading source of intra-cardiac and/or intravascular foreign bodies. Fragments of guide wires and catheters dislodged during cardiac catheterization and pacing catheters are other sources of foreign bodies. More recently coils, devices, and stents used for trans-catheter interventional procedures have added additional sources of emboli. The first documented episode of intravascular embolization of polyethylene catheter was that reported by Turner and Summers in 1954 [123]. Initial treatment approach was by surgical removal of the foreign bodies. Thomas and associates [124] were the first to document removal of an intravascular foreign body (broken guide wire) without surgery in 1964 . They retrieved the guide wire with a bronchoscopic forceps introduced via saphenous vein cut down. The first documented instance of trans-catheter retrieval of intra-cardiac foreign body in children was by Rashkind in 1969 [125].

While recognition of the problem and modifications 
of the infusion/monitoring catheter systems have resulted in a decrease in catheter emboli, new sources of emboli, namely widespread use of catheter interventional procedures, as mentioned above have emerged. Retained intravascular foreign bodies cause serious complications of arrhythmia, perforation, thrombosis, sepsis, and death. The overall risk of serious complications or death from an un-removed intracardiac foreign body is estimated to be 16 to $61 \%$ [121]. Because of this reason, and because of the availability of the trans-catheter method of retrieval, all intracardiac/intravascular foreign bodies should be removed once they are detected. There are many different types of foreign body retrieval techniques. Guide wire loop snare, helical basket, and endoscopic forceps were most commonly utilized in the retrieval in the distant past. More recently gooseneck snares (Figure 22) and other retrieval devices have been introduced. The success rate for trans-catheter removal of foreign bodies is high, at $90 \%$. The complications associated with retrieval are minimal and negligible. Prevention of embolization by meticulous attention to the technique of placing, securing, and removing intravenous catheters is of utmost importance. Due to the potential for embolization, all indwelling plastic catheters should be radiopaque so that they can be visualized by fluoroscopy and removed by trans-catheter techniques in the event of inadvertent embolization.

There has been a wide-ranging experience with percutaneous retrieval techniques in adults; however, there is limited experience in children. Nonetheless, this technique has been successfully used in pediatric patients, including neonates and premature infants. The retrieval devices were initially bulky, but there has been a reduction in their size to be of use in children. A number of modifications of the initially described techniques have been made and now they can be used to effectively retrieve most intracardiac/intravascular foreign bodies [121].

\section{References}

1. Rao PS (2020) Pediatric Cardiology: How It Has Evolved Over The Last 50 Years. Cambridge Scholars Publishing. New Castle upon Tyne, United Kingdom.

2. Rao PS (1993) Historical aspects of therapeutic catheterization. In: Rao PS, Transcatheter Therapy in Pediatric Cardiology. Chapter 1, Wiley-Liss, Inc., New York, 1-6.

3. Chopra PS, Rao PS (2000) History of the development of atrial septal occlusion devices. Curr Interv Cardiol Rep 2: 63-69.

4. Rao PS (2003) History of atrial septal occlusion devices. In: Rao PS, Kern MJ, Catheter based devices for the treatment of non-coronary cardiovascular disease in adults and children. Chapter 1, Lippincott Williams \& Wilkins, Philadelphia, PA, 3-9.

5. Alapati S, Rao PS (2012) Historical aspects of trans-catheter occlusion of atrial septal defects. In: Rao PS, Atrial Septal Defect. Chapter 5, InTech, Rijeka, Croatia, 57-84.

6. Rao PS (2012) Historical aspects of transcatheter treatment of heart disease in children. Pediat Therapeut S5: 002.

7. Rao PS (2015) History of trans-catheter interventions in pediatric cardiology. In: Vijayalakshmi IB, Cardiac Catheterization and Imaging (From Pediatrics to Geriatrics). Chapter 1, Jaypee Publications, New Delhi, India, 3-20.

8. Rao PS (2012) Congenital heart defects - A review. In: Rao PS, Congenital Heart Disease - Selected Aspects. Chapter 1, InTech, Rijeka, Croatia, 3-44.

9. Rao PS (2012) Atrial septal defect - A Review. In: Rao PS, Atrial Septal Defect. Chapter 1, InTech, Rijeka, Croatia, 3-20.

10. Rao PS, Harris AD (2017) Recent advances in managing septal defects: Atrial septal defects. F1000Res 6: 2042.

11. Sideris EB, Sideris SE, Thanopoulos BD, Ehly RL, Fowlkes JP (1990) Transvenous atrial septal defect occlusion by the buttoned device. Am J Cardiol 66: 1524-1526.

12. Rao PS, Sideris EB (1998) Buttoned device closure of the atrial septal defect. J Intervent Cardiol 11: 467-484.

13. Rao PS, Wilson AD, Levy JM, Gupta VK, Chopra PS (1992) Role of "buttoned" double-disk device in the management of atrial septal defects. Am Heart J 123: 191-200.

14. Rao PS, Wilson AD, Chopra PS (1992) Transcatheter closure of atrial septal defect by "buttoned" devices. Am J Cardiol 69: 1056-1061.

15. Rao PS, Sideris EB, Hausdorf G, Rey C, Lloyd TR, et al. (1994) International experience with secundum atrial septal defect occlusion by the buttoned device. Am Heart J 128: 1022-1035.

16. Sideris EB, Leung $M$, Yoon JH, Chen CR, Lochan R, et al. (1996) Occlusion of large atrial septal defects with a centering buttoned device: Early clinical experience. Am Heart $\mathrm{J}$ 131: 356-359.

17. Rao PS, Berger F, Rey C, Haddad J, Meier B, et al. (2000) Results of transvenous occlusion of secundum atrial septal defects with the fourth generation buttoned device: Comparison with first, second and third generation devices. International Buttoned Device Trial Group. J Am Coll Cardiol 36: $583-592$

18. Rao PS, Sideris EB (2001) Centering-on-demand buttoned device: Its role in trans-catheter occlusion of atrial septal defects. J Intervent Cardiol 14: 81-89.

19. Rao PS, Sideris EB, Chopra PS (1991) Catheter closure of atrial septal defect: Successful use in a $3.6 \mathrm{~kg}$ infant. Am Heart J 121: 1826-1829.

20. Rao PS, Ende DJ, Wilson AD, Smith PA, Chopra PS (1995) Follow-up results of transcatheter occlusion of atrial septal defects with buttoned device. Can J Cardiol 11: 695-701.

21. Lloyd TR, Rao PS, Beekman RH III, Mendelsohn AM, Sideris EB (1994) Atrial septal defect occlusion with the buttoned device (a multi-institutional U.S. trial). Am J Cardiol 73: 286-291.

22. Zamora R, Rao PS, Lloyd TR, Beekman RH III, Sideris EB (1998) Intermediate-term results of Phase I Food and Drug Administration Trials of buttoned device occlusion of secundum atrial septal defects. J Am Coll Cardiol 31: 674-676.

23. Rao PS, Sideris EB (2003) Buttoned device modifications: Influence on feasibility, safety and effectiveness. Poster presentation at the $26^{\text {th }}$ Annual Scientific Sessions of the Society of Cardiac Angiography and Interventions. Westin Copley Place, Boston, MA. Cath Cardiovasc Intervent 59: 153. 
24. Hartas GA, Balaguru D, Brown M, Rao PS (2015) Intermediate follow-up results of Amplatzer device occlusion of secundum atrial septal defects. Poster Presentation at the 19th PICS-AICS 2015, Los Vegas, NV, 2015. Cathet Cardiovasc Interv 86: 574

25. Rao PS (2009) When and how should atrial septal defects be closed in adults? J Invasive Cardiol 21: 76-82.

26. Rao PS (2000) Summary and comparison of atrial septal defect closure devices. Curr Interv Cardiol Rep 2: 367-376.

27. Rao PS (2003) Comparative summary of atrial septal defect occlusion devices. In: Rao PS, Kern MJ, Catheter based devices for treatment of non-coronary cardiovascular disease in adults and children. Chapter 1, Lippincott, Williams \& Wilkins, Philadelphia, PA, 91-101.

28. Nagm AM, Rao PS (2004) Percutaneous occlusion of complex atrial septal defects. J Invasive Cardiol 16: 123-125.

29. Rao PS (2007) Techniques for closure of large atrial septal defects. Cath Cardiovasc Intervent 70: 329-330.

30. Rao PS (2012) Why, when and how should atrial septal defects be closed in adults. In: Rao PS, Atrial Septal Defect. Chapter 8, InTech, Rijeka, Croatia, 121-138.

31. Rao PS (2014) Transcatheter closure of complex atrial septal defects. Echocardiography 31: 1173-1176.

32. Ende DJ, Chopra PS, Rao PS (1996) Transcatheter closure of atrial septal defect or patent foramen ovale with the buttoned device for prevention of recurrence of paradoxic embolism. Am J Cardiol 78: 233-236.

33. Rao PS, Palacios IF, Bach RG, Bitar SR, Sideris EB (2001) Platypnea-orthodeoxia: Management by trans-catheter buttoned device implantation. Catheter Cardiovasc Interv 54: 77-82.

34. Bitar S, Rao PS (2003) Platypnea-orthodeoxia syndrome: Transcatheter management. In: Rao PS, Kern MJ, Catheter based devices for treatment of non-coronary cardiovascular disease in adults and children. Chapter 15, Lippincott, Williams \& Wilkins, Philadelphia, PA, 129-132.

35. Rao PS, Chandar JS, Sideris EB (1997) Role of inverted buttoned device in transcatheter occlusion of atrial septal defects or patent foramen ovale with right-to-left shunting associated with previously operated complex congenital cardiac anomalies. Am J Cardiol 80: 914-921.

36. Rao PS (2003) Transcatheter closure of atrial septal defects with right-to-left shunt. In: Rao PS, Kern MJ, Catheter based devices for treatment of non-coronary cardiovascular disease in adults and children. Chapter 14, Lippincott, Williams \& Wilkins, Philadelphia, PA, 119-128.

37. Rao PS (2003) History of transcatheter patent ductus arteriosus closure devices. In: Rao PS, Kern MJ, Catheter based devices for treatment of non-coronary cardiovascular disease in adults and children. Chapter 17, Lippincott Williams \& Wilkins, Philadelphia, PA, 145-153.

38. Rao PS (2011) Percutaneous closure of patent ductus arteriosus--current status. J Invasive Cardiol 23: 517-520.

39. Naidu DP, Breinholt JP III, Rao PS (2018) Patent ductus arteriosus. In: Rajiv PK, Lakshminrusimha S, Vidyasagar D, Essentials of Neonatal Ventilation. Chapter 30B, Elsevier, 1-30.

40. Sideris EB, Sideris SE, Ehly RL (1990) Occlusion of patent ductus arteriosus in piglets by a double disk self-adjustable device. J Am Coll Cardiol 15: 240A.

41. Rao PS, Wilson AD, Sideris EB, Chopra PS (1991) Tran- scatheter closure of patent ductus arteriosus with buttoned device: First successful clinical application in a child. Am Heart J 121: 1799-1802.

42. Rao PS, Sideris EB, Haddad J, Rey C, Hausdorf G, et al. (1993) Transcatheter occlusion of patent ductus arteriosus with adjustable buttoned device. Initial clinical experience. Circulation 88: 1119-1126.

43. Sideris EB, Rey C, de Lezo JS, et al. (1996) Infant buttoned device for the occlusion of patent ductus arteriosus - early clinical experience. Cardiol Young 6: 56.

44. Rao PS, Kim SH, Rey C, Onorato E, Sideris EB (1998) Results of transvenous buttoned device occlusion of patent ductus arteriosus in adults. International Buttoned Device Trial Group. Am J Cardiol 82: 827-829.

45. Rao PS, Kim SH, Choi JY, Rey C, Haddad J, et al. (1999) Follow-up results of transvenous occlusion of patent ductus arteriosus with the buttoned device. J Am Coll Cardiol 33: 820-826.

46. Sideris EB, Rao PS, Zamora R (2001) The Sideris buttoned device for transcatheter closure of patent ductus arteriosus. J Interv Cardiol 14: 239-246.

47. Lochan R, Rao PS, Samal AK, Khanna AR, Mani GK, et al. (1994) Transcatheter closure of a patent ductus arteriosus with an adjustable buttoned device in an adult patient. Am Heart J 127: 941-943.

48. Rao PS (2001) Summary and comparison of patent ductus arteriosus closure devices. Curr Interv Cardiol Rep 3: 268274.

49. Rao PS (2003) Summary and comparison of patent ductus arteriosus closure methods. In: Rao PS, Kern MJ, Catheter based devices for treatment of non-coronary cardiovascular disease in adults and children. Chapter 25, Lippincott, Williams \& Wilkins, Philadelphia, PA, 219-228.

50. Rao PS, Sideris EB (1996) Transcatheter occlusion of patent ductus arteriosus: State of the art. J Invasive Cardiol 8: $278-288$

51. Rao PS (2001) Coil occlusion of patent ductus arteriosus. J Invasive Cardiol 13: 36-38.

52. Rao PS, Balfour IC, Chen S (1997) Effectiveness of five-loop coils to occlude patent ductus arteriosus. Am J Cardiol 80: 1498-1501.

53. Rao PS, Balfour IC, Jureidini SB, Singh GK, Chen SC (2000) Five-loop coil occlusion of patent ductus arteriosus prevents recurrence of shunt at follow-up. Catheter Cardiovasc Interv 50: 202-206.

54. Rao PS, Wagman AJ, Chen SC (2001) Coil occlusion of patent ductus arteriosus associated with right aortic arch. Catheter Cardiovasc Interv 52: 79-82.

55. Rao PS, Sharma SK (2005) Management of patent ductus arteriosus with particular attention to transcatheter therapy. In: Rao PS, Saxena A, Recent Advances in Pediatric Cardiology. Indian Journal of Pediatrics, New Delhi, India, 125139.

56. Yarrabolu TR, Rao PS (2013) Intermediate and long term follow-up after patent ductus arteriosus closure using Amplatzer device. Poster Presentation at the 17th PICS-AICS 2013, Miami, FL.

57. Tsounias E, Rao PS (2008) Versatility of Amplatzer Vascular Plug in occlusion of different types of vascular channels. Poster presentation at the $12^{\text {th }}$ Pediatric Interventional Cardiac Symposium (PICS-X) and Emerging New Technologies in Congenital Heart Surgery (ENTICHS) - 2008, The 
Bellagio, Las Vegas, NV. Catheterization and Cardiovascular interventions 71: 7 .

58. Rao PS (2007) Percutaneous closure of patent ductus arteriosus: State of the art. J Invasive Cardiol 19: 299-302.

59. Yates MC, Gautam NK, Rao PS (2015) Reactive ductus arteriosus in a nineteen month old patient. Congenital Cardiology Today 13: 1-7.

60. Gupta K, Rao PS (2005) Severe intravascular hemolysis after transcatheter coil occlusion of patent ductus arteriosus. J Invasive Cardiol 17: E15-E17.

61. Doshi AR, Rao PS (2013) Development of aortic coarctation following device closure of patent ductus arteriosus. J Invasive Cardiol 25: 464-467.

62. Samraj R, Rao PS (2011) Concurrent transcatheter therapy of valvar aortic stenosis and patent ductus arteriosus. J Invasive Cardiol 23: E72-E75.

63. Rao PS (2001) Transcatheter closure of moderate-to-large patent ductus arteriosus. J Invasive Cardiol 13: 303-306.

64. Yarrabolu TR, Rao PS (2012) Transcatheter closure of patent ductus arteriosus. Pediat Therapeut S5: 005.

65. Rao PS (2018) Role of echocardiography in the evaluation of preterm infants with patent ductus arteriosus. Neonatology Today 14: 1-10.

66. Thapar MK, Rao PS, Rogers JH Jr, Moore HV, Strong WB (1978) Changing murmur of patent ductus arteriosus. J Pediatr 92: 939-941.

67. Subramaniam U, Hamzeh RK, Sharma SK, Rao PS (2007) Reliability of echocardiographic estimation of angiographic minimal ductal diameter. Poster presentation at the $30^{\text {th }}$ Annual Scientific Session of Society for Cardiac Angiography \& Interventions, Orlando, FL. Cath Cardiovasc Intervent 69: S87.

68. Rao PS, Subramaniam U (2019) Reliability of echocardiographic estimation of angiographic minimal ductal diameter. Congenital Cardiology Today 17: 1-7.

69. Rao PS (1981) Present status of surgery in congenital heart disease. Indian J Pediatr 48: 349-361.

70. Rao PS (2012) Percutaneous occlusion of cardiac defects in children. Pediatr Therapeut 2: e107.

71. Rao PS, Harris AD (2018) Recent advances in managing septal defects: ventricular septal defects and atrioventricular septal defects. F1000Res 7: F1000.

72. Rao PS (2005) Diagnosis and management of acyanotic heart disease: Part II -- left-to-right shunt lesions. Indian J Pediatr 72: 503-512.

73. Rao PS (2013) Consensus on timing of intervention for common congenital heart diseases: Part I - Acyanotic heart defects. Indian J Pediatr 80: 32-38.

74. Rao PS (1997) The "Buttoned " Device for VSDs. Presented at the Transcatheter Devices for Congenital Heart Disease 1997. Sponsored by the University of Minnesota, Minneapolis Marriott City Center, Minneapolis, MN, 6-8.

75. Sideris EB, Kaneva A, Sideris SE, Moulopoulos SD (1998) Transarterial occlusion of ventricular septal defects by a self-adjustable device. Circulation 98: 1-755.

76. Sideris EB, Walsh KP, Haddad JL, Chen CR, Ren SG, et al. (1997) Occlusion of congenital ventricular septal defects by the buttoned device. "Buttoned device" Clinical Trials International Register. Heart 77: 276-279.
77. Sideris EB, Haddad J, Rao PS (2001) The role of the 'Sideris' devices in the occlusion of ventricular septal defects. Curr Interv Cardiol Rep 3: 349-353.

78. Holzer R, Balzer D, Cao QL, Lock K, Hijazi ZM, et al. (2004) Device closure of muscular ventricular septal defects using the Amplatzer muscular ventricular septal defect occluder: Immediate and mid-term results of a U.S. registry. J Am Coll Cardiol 43: 1257-1263.

79. Bacha EA, Cao QL, Starr JP, Waight D, Ebeid MR, et al. (2003) Perventricular device closure of muscular ventricular septal defects on the beating heart: Technique and results. J Thorac Cardiovasc Surg 126: 1718-1723.

80. Amin Z, Danford DA, Lof J, Duncan KF, Froemming S (2004) Intraoperative device closure of perimembranous ventricular septal defects without cardiopulmonary bypass: preliminary results with the perventricular technique. J Thorac Cardiovasc Surg 127: 234-241.

81. Leung MP, Beerman LB, Siewers RD, Bahnson HT, Zuberbuhler JR (1987) Long-term follow-up after aortic valvuloplasty and defect closure in ventricular septal defect with aortic regurgitation. Am J Cardiol 60: 890-894.

82. Yacoub MH, Khan H, Stavri G, Shinebourne E, Radley-Smith R (1997) Anatomic correction of the syndrome of prolapsing right coronary aortic cusp, dilatation of the sinus of Valsalva, and ventricular septal defect. J Thorac Cardiovasc Surg 113: 253-260.

83. Gu X, Han YM, Titus JL, Amin Z, Berry JM, et al. (2000) Transcatheter closure of membranous ventricular septal defects with a new Nitinol prosthesis in a natural swine model. Catheter Cardiovasc Interv 50: 502-529.

84. Hijazi ZM, Hakim F, Haweleh AA, Madani A, Tarawna W, et al. (2002) Catheter closure of perimembranous ventricular septal defects using the new Amplatzer membranous VSD occluder: Initial clinical experience. Catheter Cardiovasc Interv 56: 508-515.

85. Rao PS (2008) Perimembranous ventricular septal defect closure with the amplatzer device. J Invasive Cardiol 20: 217-218.

86. Rao PS (2018) Auscultation is still a valid tool in the evaluation of cardiac defects in children. Congenital Cardiology Today 16: 1-6.

87. Yarrabolu TR, Naidu DP, Pawelek O, Rao PS (2016) Flash pulmonary edema during pulmonary vasoreactivity testing. J J Pulmonol 2: 028.

88. Hartas GA, Gupta-Malhotra M, Rao PS. Ventricular Septal Defect complicated by subacute bacterial endocarditis after dental procedure. Poster presentation at Annual Scientific Meeting of the Texas Pediatric Society.

89. Sideris EB, Macuil B, Justiniano S, Rao PS (2005) Total percutaneous correction of tetralogy of Fallot variant with dominant pulmonary valve stenosis. Heart 91: 345-347.

90. Nathan M, Emani S, IJsselhof R, Liu H, Gauvreau K, et al. (2017) Mid-term outcomes in unbalanced complete atrioventricular septal defect: Role of biventricular conversion from single-ventricle palliation. Eur J Cardiothorac Surg 52: 565-572.

91. Siblini G, Rao PS (1996) Coil embolization in the management of cardiac problems in children. J Invasive Cardiol 8: 332-340.

92. Rao PS (2003) Transcatheter embolization of unwanted blood vessels in children. In: Rao PS, Kern MJ, Catheter based devices for treatment of non-coronary cardiovascu- 
lar disease in adults and children. Chapter 45, Lippincott, Williams \& Wilkins, Philadelphia, PA, 457-473.

93. Jureidini SB, Spadaro JJ, Rao PS (1998) Successful transcatheter closure with the buttoned device of aortopulmonary window in an adult. Am J Cardiol 81: 371-372.

94. Rao PS, Bromberg BI, Jureidini SB, Fiore AC (2003) Transcatheter occlusion of ruptured sinus of Valsalva aneurysm: Innovative use of available technology. Catheter Cardiovasc Interv 58: 130-134.

95. Rao PS (2015) Fontan operation: Indications, short and long term outcomes. Indian J Pediatr 82: 1147-1156.

96. Rao PS (2001) Stents in the management of congenital heart disease in pediatric and adult patients. Indian Heart $\mathrm{J}$ 53: 714-730.

97. Rao PS (2002) Non-Coronary uses of stents in children and adults. In: Cardiology Update, 2002. Gambhir DS, Cardiological Society of India, New Delhi, 268-282.

98. Rao PS (2003) Newer stents in the management of vascular stenoses in children. In: Rao PS, Kern MJ, Catheter based devices for treatment of non-coronary cardiovascular disease in adults and children. Chapter 39, Lippincott, Williams \& Wilkins, Philadelphia, PA, 369-378.

99. Sahu R, Rao PS (2012) Transcatheter stent therapy in children: An update. Pediat Therapeut S5: 001.

100. Rao PS (2015) Stents in the management of vascular obstructive lesions associated with congenital heart disease. In: Vijayalakshmi IB, Cardiac Catheterization and Imaging (From Pediatrics to Geriatrics). Jaypee Publications, New Delhi, India, 573-598.

101. Siblini G, Rao PS, Singh GK, Tinker K, Balfour IC (1997) Transcatheter management of neonates with pulmonary atresia and intact ventricular septum. Cathet Cardiovasc Diagn 42: 395-402.

102. Rao PS, Balfour IC, Singh GK, Jureidini SB, Chen S (2001) Bridge stents in the management of obstructive vascular lesions in children. Am J Cardiol 88: 699-702.

103. Tsounias E, Rao PS (2010) Stent therapy for clotted Blalock-Taussig shunts. Congenital Cardiol Today 8: 1-9.

104. Rao PS, Jureidini SB, Singh GK, Balfour IC, Chen S (2003) Clinical comparison of rigid with flexible stents in the management of vascular obstructive lesions in children. Cath Cardiovasc Intervent 59: 153.

105. Rao PS (2000) Pulmonary valve disease. In: Valvular Heart Disease. ( $3^{\text {rd }}$ edn), Alpert JS, Dalen JE, Rahimtoola S, Lippincott Raven, Philadelphia, PA, 339-376.

106. Rao PS (2015) Neonatal catheter interventions. In: Vijayalakshmi IB, Cardiac Catheterization and Imaging (From Pediatrics to Geriatrics). Jaypee Publications, New Delhi, India, 388-432.

107. Rao PS (2013) Stents in the management of heart disease in children. Pediat Therapeut 3: e120.

108. Rao PS (2014) Future directions in the management of aortic coarctation in young patients. Pediat Therapeut 4: e125.

109. Rao PS (2007) Role of interventional cardiology in neonates: Part I. Non-surgical atrial septostomy. Neonatology Today 2: 9-14.

110. Rao PS (2007) Role of interventional cardiology in neonates: Part I. Non-surgical atrial septostomy. Congenital Cardiol Today 5: 1-12.
111. Rao PS (2015) Catheter interventions in the neonate: Part I - Non-surgical atrial septostomy. In: Rao PS, Vidyasagar D, Perinatal Cardiology: A Multidisciplinary Approach. Chapter 19, Cardiotext Publishing, Minneapolis, MN.

112. Jureidini SB, Rao PS (1996) Critical pulmonary stenosis in the neonate: Role of transcatheter management. J Invasive Cardiol 8: 326-331.

113. Rao PS (2001) Current status of balloon angioplasty for neonatal and infant aortic coarctation. Progress Pediat Cardiol 14: 35-44.

114. Rao PS (2005) Balloon angioplasty for native aortic coarctation in neonates and infants. Cardiology Today 9: 94-99.

115. Rao PS (2007) Role of interventional cardiology in neonates: Part II - Balloon angioplasty/valvuloplasty. Neonatology Today 2: 1-12.

116. Rao PS (2008) Role of interventional cardiology in neonates: Part II - Balloon angioplasty/valvuloplasty. Congenital Cardiol Today 6: 1-14.

117. Rao PS (2015) Catheter interventions in the neonate: Part II - Balloon angioplasty/valvuloplasty. In: Rao PS, Vidyasagar D, Perinatal Cardiology: A Multidisciplinary Approach. Chapter 20, Cardiotext Publishing, Minneapolis, MN.

118. Rao PS (2007) Role of interventional cardiology in the treatment of neonates: Part III. Neonatology Today; 2: 1-10.

119. Rao PS (2008) Role of interventional cardiology in the treatment of neonates: Part III. Congenital Cardiol Today 6: 1-10.

120. Rao PS (2015) Catheter interventions in the neonate: Part III - Other interventions. In: Rao PS, Vidyasagar D, Perinatal Cardiology: A Multidisciplinary Approach. Chapter 21, Cardiotext Publishing, Minneapolis, MN.

121. Rao PS (1993) Transcatheter retrieval of intravascular/intracardiac foreign bodies. In: Rao PS, Transcatheter Therapy in Pediatric Cardiology. Wiley-Liss, Inc., New York, 377-392.

122. Meyers L (1945) Intravenous catheterization. Am J Nurs 45: $930-933$.

123. Turner DD, Sommers SC (1954) Accidental passage of a polyethylene catheter from cubital vein to right atrium: Report of a fatal case. N Engl J Med 251: 744-745.

124. Thomas J, Sinclair-Smith BC, Bloomfield DA, Davachi A (1964) Non-surgical retrieval of a broken segment of steel spring guide from the right atrium and inferior vena cava. Circulation 30: 106-108.

125. Rashkind WJ (1969) A cardiac catheter device for removal of plastic catheter emboli from children's hearts. J Pediatr 74: 618-619. 